This PDF is a selection from a published volume from the National Bureau of Economic Research

Volume Title: Scanner Data and Price Indexes

Volume Author/Editor: Robert C. Feenstra and Matthew

D. Shapiro, editors

Volume Publisher: University of Chicago Press

Volume ISBN: 0-226-23965-9

Volume URL: http://www.nber.org/books/feen03-1

Conference Date: September 15-16, 2000

Publication Date: January 2003

Title: What Can the Price Gap between Branded and Private-Label Products Tell Us about Markups?

Author: Robert B. Barsky, Mark Bergen, Shantanu Dutta, Daniel Levy

URL: http://www.nber.org/chapters/c9736 


\title{
What Can the Price Gap between Branded and Private-Label Products Tell Us about Markups?
}

\author{
Robert Barsky, Mark Bergen, Shantanu Dutta, \\ and Daniel Levy
}

\subsection{Introduction}

The magnitude of marginal costs and markups over marginal cost are empirical questions of considerable general interest in economics. Microeconomists are interested in markups because they bear on such questions as the relevance of alternative models of imperfect competition, the welfare consequences of market power, and the benefits of new product introduction. In recent macroeconomic research as well, markups play a central role (see, e.g., Hall 1986, 1988). Although macroeconomic discourse most often focuses on the cyclicality rather than the level of markups, the degree of cyclicality is often limited by the absolute size of the markup (Rotemberg and Saloner 1986).

Robert Barsky is professor of economics at the University of Michigan and a research associate of the National Bureau of Economic Research. Mark Bergen is associate professor of marketing and logistics management at the Carlson School of Management, University of Minnesota. Shantanu Dutta is associate professor of marketing at the University of Southern California. Daniel Levy is associate professor of economics at Bar-Ilan University and Emory University.

The authors are grateful to the paper's discussant, Julio Rotemberg, for his insightful comments, which played a fundamental role in the restructuring and strengthening of the argument. Susanto Basu and Matthew Shapiro provided numerous valuable suggestions and essential advice. The authors would also like to thank Ning Liu for her outstanding research assistance under a very tight schedule, Owen Beelders, Ernie Berndt, Hashem Dezhbakhsh, Jim Hess, Kai-uwe Kuhn, Jim Levinsohn, Peter Rossi, and Steve Salant for many helpful discussions, Robert Feenstra for comments, Steve Hoch for providing us with his survey data on national brand/private-label quality differences, and Jong Kim for his help with computations. They thank the participants of the NBER-CRIW conference, the 2001 Midwest Marketing Camp, and seminar participants at the University of Michigan and the University of Minnesota. Finally, the authors thank both the Kilts Center for Marketing, Graduate School of Business, University of Chicago, and Dominick's for providing us with the data. The usual disclaimers apply. 
The estimation of markups is difficult because marginal cost is not directly observable. There are essentially two ways in which inference about markups and marginal cost is approached in the econometric literature. One approach is via the cost function, which is either inferred directly from engineering data or estimated from cross-sectional or time series market data. The other is to estimate consumer demand functions and compute the markup based on estimated demand elasticities, in combination with a model of market equilibrium.

This paper takes a quite different approach to measurement of marginal costs and markup ratios. We argue that the price of a "private-label" equivalent or near-equivalent product provides valuable information about the marginal cost of the nationally branded product. In particular, because the private-label version would not sell at a price less than its marginal cost, the ratio of the price of the branded product to that of the private-label one serves as a lower bound on the markup ratio. The high relative price of national brands is thus indicative of substantial markups over marginal cost.

Underlying our approach is the notion that private-label products are more or less physically identical to nationally branded products, but the branded product commands a higher market price due to characteristics not related to marginal costs of either manufacturing or retail handling. Many of the promotional expenses that vertically differentiate the branded product from its private-label counterpart appear largely as sunk, or at least fixed, costs. Essentially the same is true of expenditure on research and development. To the extent that marginal costs of private-label goods diverge from those of the branded versions, we present evidence that suggests that manufacturing costs for the private labels are if anything higher on the margin than those for the corresponding brands.

Informed by the above considerations and in possession of data on both retail prices and the retailer's margins over wholesale, we take the wholesale price of the private-label product as an upper bound for the marginal manufacturing cost of its branded counterpart. The presumption that retailers' margins must at least cover marginal handling costs allows inference about the contribution of the retail channel to full marginal cost. We present several ratios that, under reasonable assumptions, bound the true marginal cost of manufacturing and selling the branded product from above as well as below.

We emphasize the lower-bound measure of the true markup. To briefly summarize our main results, markups computed in this manner are consistent with, but on the high side of, those found in previous studies, for the few products for which such studies exist. Markups for national brands sold in supermarkets are large. Lower bounds on markup ratios measured this way range from 3.44 for toothbrushes and 2.23 for soft drinks to about $1.15-1.20$ for canned tuna and frozen entrees, with the majority of categories falling in the range 1.40-2.10. 
The ratio of brand to private-label retail prices has on occasion been used in the literature as a measure of the markup. The texts by Scherer (1980) and Carlton and Perloff (1994) present some informally collected data of this sort. A recent paper by Nevo (1997) computes the retail price ratio as a check on structural estimation of markups on breakfast cereals and finds a markup ratio of about 1.30 , very much in accord with the estimates from the structural approach. Our data indicate, in accord with results from previous studies, that retailers earn higher margins on private labels than on national brands. This suggests that the retailer's margin on the branded variety is most likely the best indicator of actual marginal handling cost at the retail level. If this is the case, ratios of retail prices understate national brand markups over the "true" marginal cost of providing goods to the consumer.

We apply our approach to products in the grocery industry, in which there are many private-label or "store brand" products in a wide variety of categories. ${ }^{1}$ We compute our markup ratios using scanner data from the Chicago area supermarket chain Dominick's Finer Foods. The Dominick's data include both retail prices and the retailer's "margin" (and hence, implicitly, wholesale prices) for both national brands and the store brand. This allows us to decompose ratios of the retail prices into a manufacturer's markup and a retailer's markup on wholesale prices - an exercise that will prove to be important in our efforts to bound the "true" markup from above and below. The product descriptions are sufficiently detailed that we are able to identify many pairs of national brand and private-label offerings that are comparable in both quality and package size.

The paper is structured as follows. In the next section we present our conceptual framework. In subsection 7.2.1, we present a simple vertical differentiation model emphasizing the role of sunk advertising costs, consumer heterogeneity, and competition for "niche" in carving out a role for private labels and determining the size of the equilibrium markup. In section 7.2.2, we highlight the role of retail stores and point out how advertising and competition between retailers leads to an inverse relation between wholesale and retail margins. In section 7.2.3, the most critical part of the analytical section, we develop a set of inequalities involving the various price ratios and show how we can bound the true markup both above and below.

In section 7.3 we answer some possible objections about the comparability of national brand and private-label products. Evidence suggests that to the extent that there are differences, they point in the direction that prices

1. Fitzell (1998) recounts that private labels go back to the late nineteenth century and gradually developed from the sale of bulk commodity staples. From the beginning, the main focus of private-label manufacturers has been on packaged goods - packaged teas, sugar, flour, spices, and so on. Early in the twentieth century, private-label manufacturers expanded their activity by offering canned vegetables and fruits, frozen foods, and bakery and dairy products as well. Later, the private-label industry expanded to include paper products, detergents, deli items, soft drinks, health and beauty care products, and more recently even "untouchable" products such as cosmetics, baby food, natural health products, and gourmet delicacies. 
of private-label products overestimate the marginal cost of national brands - suggesting that our assumptions are in fact conservative. In section 7.4 we introduce the data and discuss measurement methods. In section 7.5 we present five different but related markup ratios, covering both the wholesale and retail levels, for over 230 comparable nationally brandedprivate-label product pairs representing nineteen categories. Computing the lower bound on markup ratios developed in section 7.2, we document that the markups for national brands are large. In section 7.6 we briefly discuss our findings, linking the variation in the magnitude of the markup ratios to the materials share in production cost. We conclude the paper in section 7.7.

\subsection{Inferring Marginal Cost and Markups From Private Labels: Theory}

\subsubsection{Vertical Differentiation and the Coexistence of Brands and Private Labels}

We begin with a very stylized example of a market with two firms, best thought of as integrated manufacturers and sellers, one producing a branded product, the other offering a physically identical unbranded product. This example is an adaptation of Tirole $(1989,296-98)$, which in turn follows Shaked and Sutton's (1982) model of vertical differentiation and price competition. Following Sutton (1991), we regard "perceived quality" as a function of the stock of past advertising A ("brand capital"). No horizontal differentiation is possible. The two firms both produce at the constant unit cost $c$. Under conditions that guarantee that the market will support both the branded and the private-label product, we derive product prices (and thus margins) as well as profits for the two firms.

Firm 1 enters the game with a stock of "brand equity" $A=\bar{A}$, which can be thought of as the return to past expenditure on advertising. Firm 2 has no brand equity: $A_{2}=0$. Although all consumers prefer the branded product at the same price, willingness to pay for the characteristics associated with the branding differs across individuals. Let this heterogeneity, which we might associate either with taste or with income differences, be parameterized by $\theta \sim U\left(\theta_{0}, \theta_{1}\right)$, where $\theta_{0} \geq 0$, and $\theta_{1}=\theta_{0}+1$. The utility of a type $\theta$ consumer is $U=\theta(1+A)-p$ if the consumer purchases one unit of the good with brand equity $A$ at price $p$, and 0 otherwise. The type $\theta$ consumer is thus indifferent between the branded and the private-label good when $\theta(1+\bar{A})-p_{1}=\theta-p_{2}$.

When we use a result from Tirole (1989), demands for the two firms as a function of the prices $p_{1}$ and $p_{2}$ are then

$$
D_{1}\left(p_{1}, p_{2}\right)=\theta_{1}-\frac{p_{1}-p_{2}}{\bar{A}} \text {, and } D_{2}\left(p_{1}, p_{2}\right)=\frac{p_{1}-p_{2}}{\bar{A}}-\theta_{0} .
$$


As $\bar{A}$ becomes large, the products become less and less substitutable, and the relative demand less and less price-sensitive.

Nash equilibrium occurs when firm $i$ maximizes $\left(p_{i}-c\right) D_{i}\left(p_{i}, p_{i}\right)$ with respect to $p_{j}(i, j=1,2)$. The prices, quantities demanded, and profits in the Nash equilibrium are

$$
\begin{array}{ll}
p_{1}=c+\frac{2 \theta_{1}-\theta_{0}}{3} \bar{A} & p_{2}=c+\frac{\theta_{1}-2 \theta_{0}}{3} \bar{A}<p_{1} \\
D_{1}=\frac{2 \theta_{1}-\theta_{0}}{3} & D_{2}=\frac{\theta_{1}-2 \theta_{0}}{3} \\
\pi_{1}=\frac{\left(2 \theta_{1}-\theta_{0}\right)^{2} \bar{A}}{9} & \pi_{2}=\frac{\left(\theta_{1}-2 \theta_{0}\right)^{2} \bar{A}}{9}
\end{array}
$$

Thus, the qualitative results are as follows:

- Firm 1 , the nationally branded incumbent, charges a higher price than the private-label firm 2 . However, both charge above marginal cost.

- The excess of price over marginal cost, and the profits of both the brand and the private-label producer, are increasing in the degree of heterogeneity in the population and in firm 1's stock of brand capital. ${ }^{2}$

- Both firms make some profit, although the national brand makes more.

\subsubsection{Adding the Retail Sector}

The stylized model above illustrates the role of brand capital and heterogeneous tastes for "perceived quality" in providing a market niche for private labels, and their effect on markups, quantity sold, and profits. However, we must now add a specific role for retailers, which are obviously central to our empirical analysis of the supermarket data. Lal and Narasimhan (1996) construct a model along the lines of the above example, but with two manufacturing firms, two retailers, and a composite outside good. Their model is intended to explain why under some conditions a manufacturer's advertising can "squeeze," that is, lower the retail margin while simultaneously increasing the wholesale margin, a point stressed previously by Steiner (1993).

Stores carry many products, and on any given purchase occasion a typical consumer buys only a subset of the products. Retailers, Lal and Narasimhan (1996) hypothesize, therefore tend to compete more aggressively based on the prices of a selected set of well-recognized nationally branded items by advertising these prices to consumers. Since the contribution to profit from any customer is the sum of revenue from advertised and unadvertised items, the intensity of retail competition, as is evident from the reflects the "principle of maximal differentiation," which is not entirely robust (Tirole 1989). 
prices of these items, increases with the amount the consumer will expend on the unadvertised items once at the store. This aggressiveness therefore translates into lower retail margins on these selected items since the retailers expect that consumers, once inside a store, will also buy non-advertised products on which the retailers receive high margins. Manufacturers who, via advertising, have established a stock of well-recognized products, are able to charge high prices to retailers. The higher margin earned by retailers on their private-label products compared with national brands is an important feature of the data we examine.

If the retail level of the channel is very competitive, retail margins are not likely to be much larger than handling costs. Many authors (such as Levy et al. 1998; Levy, Dutta, and Bergen 2002) suggest that the retail grocery industry is indeed very competitive. Retail margins on branded products are in fact very small for most product groups in our data set.

\subsubsection{Lower Bounds for Markups: Algebra ${ }^{3}$}

The "ideal" measure of the markup ratio - that which measures the extent to which quantity consumed falls short of the first best optimum-is the price paid by the consumer relative to the full marginal cost of supplying an extra unit. Denote the marginal production cost faced by the brand manufacturer as $c_{b}^{p}$ and the marginal cost the retailer faces in stocking and selling the branded product - the "marginal handling cost" —as $c_{b}^{h .}{ }^{4}$ The "full" marginal cost of providing a unit of the branded product is thus

$$
c_{b}=c_{b}^{p}+c_{b}^{h} \text {. }
$$

Consequently, we define the true markup as

$$
\mu^{*} \equiv \frac{p_{b}^{r}}{c_{b}^{p}+c_{b}^{h}},
$$

where $p_{b}^{r}$ denotes the retail price of the branded product. In this subsection, we show how to bound this ideal measure in terms of quantities that we are able to observe directly in the data on retail price and store margins.

In line with evidence presented in section 7.3, we postulate that the marginal production cost of the private label (denoted by $g$ ) is not less than that of the brand, that is,

$$
c_{b}^{p} \leq c_{g}^{p} .
$$

Because the manufacturer of the private label will not normally sell at a wholesale price less than its marginal production cost, we have

3. This section owes a major debt to our discussant, Julio Rotemberg.

4. Note that we do not make the assumption that $c_{b}^{p}$ and $c_{b}^{h}$ are constant unit costs. We do not need this assumption in our empirical work, because we are using price data to make bounding arguments rather than to arrive at point estimates of marginal costs. In particular, if there are fixed costs in production or selling that must be covered, the wholesale price and the retail price will overestimate marginal costs. 


$$
c_{g}^{p} \leq p_{g}^{w}
$$

Combining equations (3) and (4), we have

$$
c_{b}^{p} \leq p_{g}^{w} .
$$

Thus, the wholesale price of the private label is an upper bound on the marginal manufacturing cost of the brand.

Likewise, the retailer's margin on the branded product should at least cover the marginal handling costs. Letting

$$
m_{b}^{r} \equiv p_{b}^{r}-p_{b}^{w},
$$

where $p_{b}^{w}$ denotes the wholesale price of the branded product, we have

$$
c_{b}^{h} \leq m_{b}^{r} \text {. }
$$

The degree to which $m_{b}^{r}$ overstates marginal handling costs depends on the ability of the brand manufacturer to extract, on the margin, the rents associated with its brand equity. In the limit, the brand manufacturer extracts all of the rents, and $m_{b}^{r}$ equals the retailer's true marginal handling cost. ${ }^{5}$ However, since we are seeking lower bounds for the "true" markup, the logic of our argument does not in any way depend on such an assumption. Our bounds will of course be tighter if the marginal profit earned by the store on brand name goods is small. This is normally the case in practice since, as we will see in section 7.5 , for all but a few product categories the observed $m_{b}^{r}$ which must be the sum of true marginal handling cost and the store's marginal profit - is itself small.

Adding equations (5) and (7), we see that

$$
c_{b} \equiv c_{b}^{p}+c_{b}^{h} \leq p_{g}^{w}+m_{b}^{r} .
$$

Define a new ratio $\hat{\mu}$ as

$$
\hat{\mu} \equiv \frac{p_{b}^{r}}{p_{g}^{w}+m_{b}^{r}}=\frac{p_{b}^{r}}{p_{g}^{w}+p_{b}^{r}-p_{b}^{w}},
$$

where the latter equality follows from equation (6). Recalling the definition of the unobservable "true" markup as $\mu^{*} \equiv p_{b}^{r} / c_{b}^{p}+c_{b}^{h}$ from equation (2), the inequality in equation (8) implies that

$$
\hat{\mu} \leq \mu^{*} \text {. }
$$

Equation (10) is the result most central to our empirical analysis because it implies that $\hat{\mu}$ is a lower bound on the "true" or "ideal" markup. Moreover,

5. There exist some handling cost data in marketing studies that focus on direct product profitability issues. Although we have not yet obtained these cost data, they would allow us to see just how conservative our assumptions about handling costs are. Because our primary focus in this paper is on constructing a lower bound on the "ideal" markup, the main thrust of the paper would remain unchanged. See Chen et al. (1999) and Marsh Super Study Special Report (Progressive Grocer, December 1992 and January 1993) for details. We thank Jim Hess for informing us about the existence of such data. 
it shows how to construct a lower bound on the markup ratio using data directly available in the Dominick's data set. We will refer to the ratio $\hat{\mu}$ as our preferred lower-bound markup because, as we show immediately below, it is a tighter lower bound for $\mu *$ than is the ratio of the retail prices.

\subsubsection{Relationship of $\mu$ and to Retail and Wholesale Price Ratios}

It is interesting to compare the preferred markup measure $\hat{\mu}$ to the retail price ratio $p_{b}^{r} / p_{g}^{r}$ and to the wholesale price ratio $p_{b}^{w} / p_{g}^{w}$ - the former because retail prices are available in a wide variety of data sets (whereas data on retailer's margins are less common), and the latter because it is a lower bound for the manufacturer's markup over marginal production cost; that is, $p_{b}^{w} / p_{g}^{w}$ $\leq p_{b}^{w} / c_{b}^{p}$. Let $m_{g}^{r} \equiv p_{g}^{r}-p_{g}^{w}$. As section 7.5 shows, in the data it is almost always the case that

$$
m_{b}^{r} \leq m_{g}^{r},
$$

that is, the retailer earns less revenue net of the wholesale price from selling a unit of the national brand than from selling a unit of the comparable private label. When equation (11) holds, we can see, by combining equations (8) and (11), and using equations (5) and (7), that

$$
c_{b} \equiv c_{b}^{p}+c_{b}^{h} \leq c_{b}^{p}+m_{b}^{r} \leq p_{g}^{w}+m_{g}^{r}=p_{g}^{r} .
$$

The retail price of the private label is an upper bound for the full marginal cost of the brand; it is, however, a less tight upper bound than the preferred marginal cost measure that appears in the denominator of $\hat{\mu}$. Hence, the markup measure based on retail prices, $\mu^{r} \equiv p_{b}^{r} / p_{g}^{r}$, is a lower bound for the true markup $\mu^{*}$ and understates $\mu^{*}$ to a greater extent than does $\hat{\mu}$.

Finally, it is easy to see that the markup measure based on wholesale prices, $\mu^{w} \equiv p_{b}^{w} / p_{g}^{w}$, satisfies $\mu^{w} \geq \hat{\mu}$. Recall that $\hat{\mu} \equiv p_{b}^{r} / p_{g}^{w}+m_{b}^{r}$. To go from $\hat{\mu}$ to $\mu^{w}$, we subtract $m_{b}^{r}$ from both the numerator and the dominator. Since markup ratios exceed unity, the subtraction has a larger percentage effect on the denominator than the numerator. It is not, however, possible to say that $\mu^{w}$ is unambiguously an upper bound for $\mu^{*}$, because we don't know the extent to which $p_{g}^{w}$ and $m_{b}^{r}$ exceed, respectively, the true marginal production cost and marginal handling cost of the national brand.

In summary, we report five markup ratios:

1. $\hat{\mu} \equiv p_{b}^{r} / p_{g}^{w}+m_{b}^{r}$, the "preferred" lower-bound measure of the full markup on the brand,

2. $\mu^{r} \equiv p_{b}^{r} / p_{g}^{r}$, the lower-bound measure of the full markup based on retail prices,

3. $\mu^{w} \equiv p_{b}^{w} / p_{g}^{w}$, the lower-bound measure of the manufacture's markup ratio based on wholesale prices,

4. $\mu_{b} \equiv p_{b}^{r} / p_{b}^{w} \equiv m_{b}^{r} / p_{b}^{w}+1$, the "retailer's markup" ratio on the brand, and finally,

5. $\mu_{g} \equiv p_{g}^{r} / p_{g}^{w} \equiv m_{g}^{r} / p_{g}^{w}+1$, the "retailer's markup" ratio on the private label. 
Table 7.1 Notation Used in Deriving the Lower Bounds for Markups

\begin{tabular}{ll}
\hline$c_{b}^{p}$ & Marginal production cost of the branded product \\
$c_{g}^{p}$ & Marginal production cost of private label \\
$c_{b}^{h}$ & Retailer's "marginal handling cost" of the branded product \\
$c_{b}$ & The "Full" marginal cost of providing a unit of the branded product \\
$p_{b}^{r}$ & Retail price of the branded product \\
$p_{g}^{r}$ & Retail price of private label \\
$p_{g}^{w}$ & Wholesale price of private label \\
$p_{b}^{w}$ & Wholesale price of the branded product \\
$m_{b}^{r}$ & Retailer's margin on branded product \\
$m_{g}^{r}$ & Retailer's margin on private label \\
$\mu^{*}$ & The "true" or the "ideal" markup \\
$\hat{\mu}$ & The "preferred" lower bound on the "true" markup \\
$\mu^{r}$ & The lower-bound markup based on retail prices \\
$\mu^{w}$ & The lower-bound markup based on wholesale prices \\
$\mu_{b}$ & The retailer's markup on the branded product \\
$\mu_{g}$ & The retailer's markup on private label \\
\hline
\end{tabular}

The first three ratios, along with the "true" underlying markup ratio $\mu^{*} \equiv$ $p_{b}^{r} / c_{b}^{p}+c_{b}^{h}$, satisfy the inequalities

$$
\mu^{r} \leq \hat{\mu} \leq \mu^{w}
$$

and

$$
\mu^{r} \leq \hat{\mu} \leq \mu^{*} .
$$

In table 7.1, we summarize the algebraic notation used in this section for deriving the lower bounds on the markup ratio.

\subsection{Branded and Private-Label Products: Issues of Comparability}

In section 7.2, we established algebraic conditions under which the ratios we report can be considered lower bounds on the true markup. The usefulness of our arguments depends, however, on the maintained hypothesis that neither the marginal production cost nor the marginal handling cost of the branded product exceeds that of the private-label version. The appropriateness of this assumption is an empirical question whose answer may differ across product categories. In this section we consider three potential objections to the approach in this paper:

- Private-label goods are inferior products produced at lower cost using cheap, low-quality inputs (the "physical quality" objection).

- Differences in production technique, scale, and factor prices make variable costs in the manufacturing process noncomparable even when the final outputs are comparable (the "production method" objection).

- Even if the private-label product is physically comparable to the nationally branded version, the activities of advertising and otherwise 
promoting the national brand (and perhaps also expenditures on research and development) may create additional marginal costs for national brands (the "marketing cost" objection).

All three of these objections concern the comparability of the national brand and the store brand versions, and all potentially call into question the supposition that marginal production and marketing costs for the privatelabel product are at least as great as those for their branded counterparts. In the three subsections that we follow, we take up these objections in turn.

\subsubsection{Physical Quality}

This subsection has two purposes. First, it presents evidence that privatelabel products are not in general of lower physical quality than the corresponding national brands. For the purposes of this paper, this is of interest not in and of itself, but because a finding of low quality in tests by quality control managers and consumer organizations might indicate the use of lower quality inputs, and hence lower marginal cost.

Second, although private-label products are not in general physically inferior, there is some evidence of variation in the relative quality of brands and private labels across product categories. Thus we discuss in this section our efforts to weed out categories in which there are in fact problems of comparability that make it difficult to construct matching pairs of physically identical products.

Branded and private-label versions of a product cannot be economically identical, as that would violate the law of one price. The first objection from the earlier list concerns possible differences in the quality of the physical product and not differences in "perceived quality" associated with sunk advertising costs, as discussed by Sutton (1991). Further, because the relevant concern is with differences in marginal costs, it is in fact not necessary that the private-label product be of equal physical quality in all respects. Superior designs or propriety formulas that do not affect marginal cost do not pose a problem. We focus on "quality" to the extent that low quality of the private-label product is suggestive of the use of lower cost inputs. We identify product categories in which this appears to be an issue, and we avoid these in the empirical work reported in sections 7.4 and 7.5.

Hoch and Banerji (1993) note the absence of a secondary data source on private-label quality comprehensive enough to cover all the SAMI (Selling Areas Marketing, Inc.) product categories. For example, Consumer Reports does not have quality ratings for all the products included in our data set. Therefore, it undertook a survey of quality assurance managers at the fifty largest supermarket chains and grocery wholesalers in the United States (according to Thomas Food Industry Register). These experts typically have a graduate education in food science and wide experience testing numerous product categories. For each of the original SAMI categories the managers 
Product Quality Ratings by Category

\begin{tabular}{lc}
\hline Product Category & Quality Rating of Private Label \\
\hline Analgesics & 4.8 \\
Toothbrushes & 4.7 \\
Frozen Juices & 4.7 \\
Cereals & 4.7 \\
Oatmeal & 4.7 \\
Crackers & 4.6 \\
Cheeses & 4.6 \\
Frozen Entrees & 4.6 \\
Canned Tuna & 4.5 \\
Fabric Softeners & 4.5 \\
Bottled Juices & 4.5 \\
Laundry Detergents & 4.4 \\
Snack Crackers & 4.4 \\
Cookies & 4.3 \\
Grooming Products & 4.3 \\
Dish Detergents & 4.2 \\
Toothpaste & 4.2 \\
Canned Soup & 4.1 \\
Bathroom Tissues & 4.1 \\
Soft Drinks & 4.0 \\
\hline
\end{tabular}

Source: Hoch and Banerji (1993), unpublished data.

Notes: Quality ratings range from 1 to 5. " 1 " means that the private label is much worse in quality than the corresponding national brand, while " 5 " means that the private-label quality is fully comparable to that of national brand.

were asked: "How does the quality of the best private-label supplier compare to the leading national brands in the product category?" The respondents gave a rating on a five-point scale: a "1" suggests that private labels are much worse in quality than the national brands, whereas a " 5 " suggests that the private-label quality is fully comparable to that of the national brand. ${ }^{6}$ In table 7.2, we report the means of these survey-based quality ratings for each of the categories that we examine in the Dominick's data.

Hoch and Banerji's $(1993,62)$ own evaluation of the evidence is that "the overriding sentiment of these experts was that quality of the best private label was quite close to that of the national brands." This is consistent with industry observers (e.g., Quelch and Harding 1996; Fitzell 1998) who suggest that although over the long haul private-label products have not consistently exhibited the uniformly high quality standards as national brands, in

6. Hoch and Banerji contacted each of these managers by telephone to solicit their participation and followed up with a questionnaire. Thirty-two people (64 percent) returned the survey, resulting in twenty-five usable sets of responses ( 50 percent). The experts received a onepage set of instructions explaining what is meant by each question and how to use the scales. They were instructed to evaluate "objective" quality rather than quality as perceived by customers. 
recent years private-label products have significantly improved in quality and packaging enhancements, making them comparable to the national brands. The quality comparability of private-label products in these categories is further reinforced by a survey that asks consumers about their perceptions of the quality premium that national brands offer relative to private labels (Sethuraman and Cole 1997). This study finds that consumers are willing to pay a price premium for national brands even though they are aware that the price premiums do not reflect corresponding quality differences.

It is important to stress that the label "Dominick's Finer Foods" is in itself a kind of branding that differentiates the supermarket chain's products from true generics. The very particular sort of branding practiced by Dominick's and other supermarket chains makes no attempt to provide the utility-yielding associations that are the object of much national advertising. It may, however, do a very good job of assuring physical quality. According to Fitzell (1998), private-label owners do not compromise on quality because they cannot really afford to put a store name or their own brand name on a product that may be considered inferior. Use of a name such as Dominick's serves a bonding function: if one good (or the services of one store) proves to be inferior or unpalatable, there is a spillover on the credibility of all goods and all stores carrying that label.

Finally, we can use Hoch and Banerji's private-label quality ratings along with other information to identify categories in which quality differences are more likely so that we can learn whether or not the quality differences are likely to indicate lower variable costs for the private-label version. To that end we undertook further study of the two product categories that were ranked lowest by Hoch and Banerji's survey and that are also included in the Dominick's data: bathroom tissue and soft drinks.

\section{Bathroom Tissue}

This was one of the lowest-rated categories in terms of quality comparability. Thus the higher markups may, in this category, represent true input quality differences and therefore differences in marginal costs. There exists a recent Consumer Reports article on bathroom tissue as well as recent academic paper by Hausman (1999) on the category. Both of these, as well as a survey of consumer perceptions by Sethuraman and Cole (1997), reinforced the belief that this category does indeed have significant quality variation. The Consumer Reports article reported studies of many products that ranged broadly from Ultra Plush Charmin to low-quality private-label products and Scott tissue. Hausman (1999) echoes the claim that some brands are of low quality whereas others are of high quality. Consistent with this, Sethuraman and Cole (1997) find that consumers rate bathroom tissue as one of the two product categories for which the quality gap as perceived by consumers is highest. Further, Hausman (1999) suggests that this 
is due to real differences in input quality in the pulp used to make the paper, which is likely to lead to higher costs for higher-quality branded manufacturers in this category. We thought this might allow us to compare the private-label Scott, but Scott turns out to have many more sheets per role than the private label, making it possible that Scott faces higher costs because of the additional sheets, even if the input costs are the same or lower. In the end this additional information led us to drop the bathroom tissue category from this paper (although the price ratios in this category averaged above 2.0). We were not able to find national brand/private label pairs that were of comparable quality and for which we were confident that the private-label product was not cheaper to produce on the margin.

\section{Soft Drinks}

According to our quality experts, soft drinks are one of the least comparable categories in terms of quality based on quality control manger's perceptions. To the degree that the quality differences relate to cost savings for the private label, this would inflate our markup estimates. However, to the degree that the differences in quality are in terms of taste or other inputs into the syrup, they are unlikely to lead to substantial differences in variable costs. We include soft drinks in this paper because knowledge of the nature of soft drink production and distribution suggests that the sources of quality differences were not likely to be related to the marginal costs faced by soft drink manufacturers. In this category the majority of the costs are bottling and distribution. The cost of the syrup is only a very small portion of the cost of producing soft drinks (Levy and Young 2001).

\subsubsection{Production Methods, Scale, Factor Prices, and Other Cost Differences}

Even if the final products are physically identical, marginal manufacturing costs may differ because of differences in production technology, scale, or the prices paid for labor or materials. We report here some observations concerning differences between national brand manufacturers and manufacturing firms that supply output for sale under private labels - referred to in the industry as "co-packers."

We interviewed a number of industry experts on private labels. Their general sense was that for products of equal quality, the variable costs of producing private labels were likely to be at least as high as, and probably higher than, the corresponding costs for national brands. The general tenor of the responses we received is captured by the following comment from the vice-president of a major private-label food broker: "National brands should be able to physically produce at a lower cost. . . [T]hey are able to negotiate lower prices on components and vertically integrate to carry out processes themselves rather than having to buy at higher marginal cost." 
Below we describe in more detail the nature of manufacturing by copackers and its implications for marginal costs.

\section{Types of Private-Label Manufacturers}

As spelled out on the web page of the Private Labels Manufacturers Association, private-label manufactures fall into four categories:

1. Large national brand manufacturers that utilize excess plant capacity to supply store brands

2. Small, quality manufacturers that specialize in particular product lines and concentrate on producing store brands almost exclusively. Often, these companies are owned by corporations that also produce national brands.

3. Major retailers and wholesalers that own their own manufacturing facilities and provide store brand products for themselves

4. Regional brand manufacturers that produce private-label products for specific markets

In general, private-label manufacturers are smaller, more regional, and more fragmented than their national brand counterparts. Indeed, according to Fitzell (1998), as private-label manufacturing evolved in the United States, the trend has been more toward smaller manufacturers and processors. As a result, the national brand business, with its high costs of product development and marketing, was left to the larger manufacturers. For example, some of the producers for TOPCO (which handles distribution for what is perhaps the largest private-label program in the country) are large enough to produce and market products successfully under their own brands. In many cases, however, it turns out that they are small or mediumsized producers that lack the necessary financial strength or organizational structure to market their own brand products effectively when facing strong national competitors (Fitzell 1998).

We interviewed at some length a production manager at a large branded manufacturer in the consumer packaged goods industry. Although he preferred to remain anonymous, he expressed the belief that everything he shared with us is common knowledge in the industry.

This manager noted that at one time or another, most co-packers produce for branded manufacturers. To that end, private-label manufacturers would have access to the same equipment and techniques as manufacturers of the brand because they must meet the quality standards of the national brand manufacturers for which they produce. Further, he said, branded manufacturers supply some of the equipment for their co-packers. These observations are also found in the Federal Trade Commission complaint against the proposed merger of General Mills with Ralcorp, which was at the time (1997) both the fifth largest supplier of ready-to-eat breakfast cereal for sale under a national brand name and the largest producer of private-label cereals. 
Our interviewee described three major considerations determining relative production cost, which he called throughput, crewing, and wage rates. Throughput appears to be industry terminology for number of units produced per hour, and crewing apparently refers to labor intensity. It is not clear that these are entirely separate considerations from the point of view of microeconomic theory, but we will try to stick as closely as possible to the terminology used by the interviewee.

The manager contended that throughput for branded manufacturers is significantly higher than for co-packers, whereas crewing is indicative of greater automation and lower labor intensity in production of branded products. First and foremost, private-label manufacturers are smaller in scale. Second, private-label manufacturers, by the nature of their business, need to be more flexible with respect to the quantities they produce. They often supply multiple private labels, and uncertain demand calls for a degree of flexibility that limits their ability to benefit from large-scale production runs and the economies of scale of the brand manufacturer. This leads to lower line speeds and lower throughput for private-label manufacturers.

As to crewing, branded product factories have greater automation than private-label factories, an observation that the manager regarded as central to his belief that brand manufacturers produce at a lower variable cost. Relative to the private-label manufacturers, branded firms have fewer employees and more equipment per unit of output. Wage rates, on the other hand, work in the opposite direction: here, brand manufacturers are at a cost disadvantage. They are more likely to use union workers, which raises cost, in terms of wages and benefits. This is closely related to the "large firm effect" on wages in the academic literature (Brown and Medoff 1989). The manager's sense was that the throughput advantage roughly offset the wage disadvantage for an equal crew size. However, the branded manufacturer had a sufficiently lower labor intensity — a crewing advantage — that more than offset the higher wages.

The value of size for national brands has been noted in academic studies as well. For example, Schmalensee (1978) has shown that national brands benefit from the substantial economies of scale in production and advertising that accrue through national distribution in the cereal category. Likewise, Brown and Medoff (1991) have shown that larger buyers receive substantial quantity discounts on their purchases, although this advantage is again offset to a greater or lesser extent by higher wage costs.

In sum, industry experts as well as academic articles regard the preponderance of the evidence as indicating that marginal costs for private-label products are at least as high as - and in many cases higher than - marginal costs for the national brands with which they are paired. This conclusion supports our use of wholesale prices of private-label goods as upper bounds for the marginal manufacturing cost of the corresponding brand name products. 


\subsubsection{The Marketing Cost Issue}

A third potential difference between national brands and private labels concerns costs of product introduction and marketing. Industry sources indicate that in general private-label manufacturers do far less in terms of research and development (R\&D), advertising, trade promotion, and consumer promotion than national brands. For example, Fitzell (1998) states that national brand businesses have high costs of product development and marketing.

This leaves us with the remaining question of how large these costs are and whether they are fixed or variable costs in nature. We argue that R\&D is a sunk cost and that national advertising expenditure constitutes predominantly a fixed cost, much but not all of which can be regarded as sunk in the sense of Sutton (1991). This leaves trade promotion spending and consumer promotion spending as possible variable cost differences we must consider. Notice that the largest effect of both trade promotions and consumer promotions is the reduced price the manufacturer receives from the promotions. Thus, they aren't marginal cost differences but adjustments to the prices the manufacturer receives that we must consider. There are additional costs of implementing the promotional programs that we should also consider.

\section{Research and Development}

Research and development is one area in which private labels and national brands differ substantially. For example, according to Fitzell (1982), $\mathrm{R} \& \mathrm{D}$ expenditures of private-label manufacturers usually are substantially lower than the expenditures of the national brand manufacturers. The managers of national brands see these kinds of expenditures as critical to maintaining their brand equity. Clearly R\&D spending for new product development is not marginal for products being sold in grocery chains. According to Monroe (1990), as well as many other authors, R\&D costs do not vary with the (sales) activity and are not easily traceable to a product or segment, and therefore they should be treated as fixed from our perspectives.

\section{Advertising}

Advertising spending is another major difference between national brands and private labels. National brands invest large amounts of money in advertising. For example, in the survey of Leading National Advertisers in Advertising Age magazine (2000), it is reported that advertising spending for major brands is substantial. Further, many brands have been investing substantially on advertising for many years. Indeed, according to Quelch and Harding (1996), it took decades of advertising by the strongest national 
brands to build their consumer equities. As another example, it seems that restrictions on television advertising may help explain the strength of private labels in Europe relative to the United States because "regulated television markets mean that cumulative advertising for brand names does not approach the U.S. levels" (Quelch and Harding 1996).

This has not been true for most private labels because their owners could not afford the expense of building their own brand equity by adopting multimillion-dollar advertising campaigns (Fitzell 1998). In the case of the specific retailer we are studying, we know that it did not invest anywhere near the amounts spent by the national brand manufacturers of comparable products, even on a per-unit sold or sales basis, on advertising to build brands.

The question, then, is whether it is more reasonable to treat advertising expenditures by manufacturers as a fixed cost or variable cost. If we suppose for a moment that the branded variant is heavily advertised but the privatelabel version is not, the average cost of a unit sold (which includes costs incurred by the "marketing department" in addition to those of the "production department") would be higher for the branded product. The question, put differently, then becomes whether advertising should be seen as a marginal cost as opposed to a fixed or sunk cost.

The best evidence we could find on this question in the literature is from the Cox Annual Survey of Promotional Practices (1996). It surveys consumers, packaged goods manufacturers, and grocery retailers on issues of promotion practice and usage. The particular survey was conducted in 1995 and its participants included 34 percent larger firms (i.e., those with annual sales of $\$ 1$ billion or more) and 66 percent smaller firms (i.e., those with annual sales of less than $\$ 1$ billion).

When asked about the share of national advertising programs designed to support and build brand equity, consumer and trade promotions, and the like, the survey participants state that they view their advertising expenses as mostly aimed at building brand equity, which is more of a fixed or longrun cost. According to the survey results, the packaged goods manufacturers believe that at least 66 percent of their advertising spending is meant to build their brand equity only. Of the remaining 34 percent, 14 percent of their advertising spending is devoted to both brand equity and consumer promotions, 7 percent to both brand equity and trade promotions, and the remaining 13 percent to brand equity, trade, and consumer promotions. It follows that up to 80 percent of advertising is related to brand equity. Morton and Zettelmeyer (2000) also emphasize the difference in fixed costs between national and store brands. The advertising required to support national brands, they argue, implies that national brand manufacturers have substantially higher average costs than their marginal costs of production. This is consistent with the idea that advertising by national brands may be viewed as a fixed, rather than variable, cost. 


\section{Trade Promotions}

Manufacturers also invest heavily in trade promotions. In the Cox survey they report some industry averages on how firms in the grocery industry allocate their promotional dollars. It looks to be about 50 percent trade promotions, 25 percent national advertising, and 25 percent consumer promotions. Thus, trade promotions are the largest component of manufacturer spending. Private-label manufacturers do not undertake nearly as much trade spending, so this is another major difference between national brands and private labels.

Fortunately the Dominick's data already incorporate some of the trade spending in its wholesale prices, so we have already taken part of manufacturer's trade promotion spending into account in our measurement of national brand markups. It is likely that there are trade promotions that are not captured by the wholesale prices in our data. These are most likely lumpy payments such as slotting allowances, cooperative advertising allowances, and various case discounts and spiffs the manufacturer gives to the retailer. To the degree that they are lumpy and not incorporated into the wholesale price that retailers are using in their pricing decisions, however, it is not clear that these expenses are truly variable. Thus, these unreported trade expenditures may not be as relevant as the trade promotions incorporated into the data we use in this paper. However, to the degree that the unreported trade spending is variable, and substantial, our measure of markups will be overstated.

\section{Consumer Promotions}

This is also a major difference between national brands and private labels. Private labels tend not to use coupons or promote to consumers, as discussed by Slade (1998), whereas branded manufacturers spend, on average, 25 percent of their promotional expenses on consumer promotions. That is about on par with the amount spent on national advertising.

These activities are likely to be either reductions in the price manufacturers receive (as with redeemed coupons) or variable expenses to run the promotion. Although scanner data sets often include some measures of usage of manufacturers' coupons, that is not true in this data set. To give the reader some sense of how important these may be by category, we report the percentage of sales made using a coupon for all product categories we study in table 7.3.

In summary, we believe there is enough evidence to suggest that using private-label product prices to infer national brand costs is a reasonable assumption in this industry. There is reason to believe, therefore, that this measure of markup can be appropriate for at least some categories and products in this industry. Further, since the private label will have some 
Table 7.3

Manufacturer Coupon Usage by Product Category

\begin{tabular}{lc}
\hline Product Category & \% Sales with Manufacturers Coupon \\
\hline Analgesics & 10.6 \\
Toothbrushes & 12.5 \\
Frozen Juices & $1.7-5.9$ \\
Cereals & 16.5 \\
Oatmeal & 9.9 \\
Crackers & $0.8-5.3$ \\
Cheeses & $2.6-6.6$ \\
Frozen Entrees & $2.5-16.5$ \\
Canned Tuna & 0.6 \\
Fabric Softeners & $14.2-16.3$ \\
Bottled Juices & $0.7-2.1$ \\
Laundry Detergents & 14.0 \\
Snack Crackers & 6.4 \\
Cookies & 3.9 \\
Grooming Products & 9.4 \\
Dish Detergents & 12.3 \\
Toothpastes & 13.6 \\
Canned Soup & 6.5 \\
Bathroom Tissues & 4.8 \\
Soft Drinks & 2.2 \\
\hline
\end{tabular}

Source: Supermarket Business, 16th Annual Product Preference Study (1993).

markup, and the nationally branded products have advantages on size and scale in production, packaging, and negotiation on input prices, we believe that private-label product prices provide a conservative measure of these costs.

\subsection{Data}

We use scanner data from Dominick's Finer Food (DFF), which is one of the largest retail supermarket chains in the larger Chicago metropolitan area, operating ninety-four stores with a market share of about 25 percent. Large multistore U.S. supermarket chains of this type made up about $\$ 310,146,666,000$ in total annual sales in 1992 , which was 86.3 percent of total retail grocery sales (Supermarket Business 1993). In 1999 the retail grocery sales had reached $\$ 435$ billion (Chevalier, Kashyap, and Rossi 2000). Thus the chain we study is a representative of a major class of the retail grocery trade. Moreover, Dominick's-type multistore supermarket chains' sales constitute about 14 percent of the total retail sales of about $\$ 2,250$ billion in theUnited States. Since retail sales account for about 9.3 percent of the gross domestic product (GDP), our data set is a representative of as much as 1.28 percent of the GDP, which seems substantial. Thus 
the market we are studying has a quantitative economic significance as well.

The original Dominick's data - which have been used also by Chevalier, Kashyap, and Rossi (2000); Müller et al. (2001); Dutta, Bergen, and Levy (2002); and Levy, Dutta, and Bergen (2002) — consist of up to 400 weekly observations of actual transaction prices in twenty-nine different categories, covering the period from 14 September 1989 to 8 May 1997. The length of individual product price time series, however, varies depending on when the data collection for the specific category began and ended. Note that Dominick's Universal Product Code-level database does not include all products the chain sells. The database we use represents approximately 30 percent of Dominick's revenues (Chevalier, Kashyap, and Rossi 2000). The data come from the chain's scanner database, which contains actual retail transaction prices of the products along with the profit margin the supermarket makes on each one of them. From the information on retail prices and the profit margin, we have constructed the weekly time series of wholesale prices.

The retail prices are the actual transaction prices: the prices customers paid at the cash register each week. If the item was on sale, then the price data we have reflect the sale price. Although the retail prices are set on a chain-wide basis at the corporate headquarters of Dominick's, there may still be some price variation across the stores depending on the competitive market structure in and around the location of the stores (Levy et al. 1998). According to Chevalier, Kashyap, and Rossi (2000), Dominick's maintains three such price zones. Thus, for example, if a particular store of the chain is located in the vicinity of a Cub Food store, then the store may be designated a "Cub-fighter" and, as such, it may pursue a more aggressive pricing policy in comparison to the stores located in other zones. In the analysis described below we have used all the data available from all stores by properly aggregating them across the stores. Note that our retail prices reflect any retailer's coupons or discounts but, as mentioned above, do not include manufacturer coupons.

The wholesale prices, which measure the direct cost to the retailer, are computed by combining the retail price data with the information provided by the retailer on its weekly gross margins for each product and using the relation wholesale price $=(1-$ gross margin percent $)$ multiplied by the retail price. The wholesale prices DFF uses for computing its gross margin series are constructed by the retailer as a weighted average of the amount the retailer paid for all its inventory. For example, a profit margin of 25.3 means that DFF makes 25.3 cents on the dollar for each item sold, which yields a cost of good sold of 74.7 cents. If the retailer bought its current stock of Kellogg's Corn Flakes, 18-oz., in two transactions, then its wholesale price is computed as the average of these two transaction prices (no FIFO [First In, 
First Out] or LIFO [Last In, First Out] accounting rules are used in these computations). ${ }^{7}$

For the purpose of this study, we went through DFF's entire data set and identified pairs of national brand and private-label products. Of the approximately 350 pairs we were able to locate in the twenty-nine product categories, we have eliminated a portion of them because of substantial size differences. For example, if, say, in the cereals category we compare Kellogg's corn flakes to DFF's corn flakes, but the national brand comes in a 32 -oz. box (which is a family size) and DFF's product comes in an 18-oz. box, then the two products are not really comparable because they are targeted to two different kinds of customers, and computing prices per ounce would not necessarily eliminate this fundamental problem. Other pairs were eliminated because many non-private-label brands did not really qualify as national brand products because these products are marketed only regionally (and some even locally only) or they did not have substantial market share. Still other pairs were eliminated because of our uncertainty about equality of their quality. Finally, we have imposed a minimum on the length of the weekly time series for them to be informative.

Thus, the results we report in this paper are for national brand/privatelabel product pairs, such that (a) the national brand product is clearly marketed nationally; (b) the national brand product is widely recognized; (c) the national brand product has a nontrivial market share; (d) the national brand/private-label product pair is comparable in size, quality, and packaging; and (e) the price time series for the product pairs are available for at least a twenty-four-week period for each of the three price zones.

The product pairs that pass these criteria represent nineteen categories, which include analgesics, bottled juices, cereals, cheeses, cookies, crackers, canned soups, dish detergent, frozen entrees, frozen juices, fabric softeners, grooming products, laundry detergent, oatmeal, snack crackers, toothbrushes, toothpastes, soft drinks, and canned tuna. In the case of the soft

7. Thus, the wholesale costs in the data do not correspond exactly to the replacement cost or the last transaction price. Instead we have the average acquisition cost (ACC) of the items in inventory. So the supermarket chain sets retail prices for the next week and also determines $\mathrm{AAC}$ at the end of each week, $t$, according to the formula

$$
\begin{aligned}
\operatorname{AAC}(t+1)= & (\text { Inventory bought in } t) \text { Price paid }(t) \\
& +[\text { Inventory, end of } t-1-\operatorname{sales}(t)] \operatorname{AAC}(t) .
\end{aligned}
$$

There are two main sources of discrepancy between replacement cost and AAC. The first is the familiar one of sluggish adjustment. A wholesale price cut today only gradually works itself into AAC as old, higher-priced inventory is sold off. The second arises from the occasional practice of manufacturers of informing the buyer in advance of an impending temporary price reduction. This permits the buyer to completely deplete inventory and then "overstock" at the lower price. In this case AAC declines precipitously to the lower price and stays there until the large inventory acquired at that price runs off. Thus, the accounting cost shows the low price for some time after the replacement cost has gone back up. 
drinks category, it should be noted that most of the nationally branded products included in this category are handled by their manufacturers through various direct store delivery arrangements. ${ }^{8}$ Thus, the "handling costs" of these nationally branded products are incurred by their manufacturers. ${ }^{9}$ Therefore, to get a markup ratio, in this case, we would take the ratio of the retail price of the nationally branded product over our estimate of the marginal cost of the branded product, calculated as the sum of the wholesale price of the private-label product and our estimate of the retailer handling cost. We, however, choose to treat the soft drink products and the rest of the products in an identical fashion by using the same formula for measuring the markup ratio. Therefore, by including in the denominator of the markup ratio the retailer's margin on the nationally branded product, we are overestimating the retailer's handling cost by counting the retailer's profit as part of the marginal cost. The resulting markup measure for the soft drink products will, therefore, be even more conservative than for the rest of the categories.

To compute the average markup figures for each category, which we report in figures 7.1-7.6, we had to compress the data by using three different weighted-averaging procedures. First, we have computed the weighted average of all weekly price series across all the chain's stores to get a single weekly wholesale and retail price series for each of the national brand and private-label products chosen for the analysis. The purpose of the weighing procedure we have implemented is to ensure that the price series coming from the stores that sell proportionally more than others receive higher weight. This averaging was done by weighing the national brand and private-label price series from each store according to the store's sales share in the total DFF sales where the sales are measured by the weekly sales figures of the specific national brand and private-label products, respectively. Since the scanner database does not include information on the quantities purchased at the wholesale level, we used the retail sales figures as its proxy. This procedure likely introduces a noise in the generated series because the retail sales are more spread over time in comparison to wholesale purchases, which occur with lower frequency. The noise, however, will mostly

8. Most big retail supermarket stores use some kind of dedicated warehouse channel distribution system for their product replenishment. However, for a number of reasons, the retailers often find it preferable to obtain some products directly from the suppliers or manufacturers who deliver them directly to the store, rather than via their normal warehouse channel. The products handled through such direct store delivery mechanisms usually are high-volume, fast-moving, or perishable products. See Levy et al. (1998) for further details on direct store delivery arrangements at multiproduct retail settings.

9. In the remaining ten categories, which include bath soap, beer, cigarettes, front-end candies, frozen dinners, paper towels, refrigerated juices, shampoos, soaps, and bathroom tissues, we were unable to find comparable national brand/private-label pairs. That is, in these categories we were unable to find any national brand/private-label product pair that met all five criteria listed above. 
affect the weekly volatility properties of the price series, but the average values are unlikely to be affected from this procedure in a significant way.

Next, we computed the weighted average weekly values of the above across-store weighted averaged series by taking each price series for the sample period it was available and computing its weekly average value by weighing each weekly observation according to the share of that week's quantity sold in the total quantity sold over the entire sample period. As before, the purpose of this weighing is to give higher weight to observations (i.e., weeks) that represent higher sales volume measured in terms of products' quantity (such as ounces). In each case the prices of national brand products were weighed using the sales volume of that specific national brand product, whereas the price series of the private-label products were correspondingly weighed by sales volume of the private-label products. These series were then used to compute various markup measures reported in tables 7A.1-7A.19.

It should be noted that an alternative way of computing these weekly average markup values for each national brand/private-label product pair is to first compute weekly markup series for the entire sample period covered by each product pair and then compute their weekly weighted average using the procedure outlined above. The calculations performed using this procedure have yielded similar quantitative results in terms of the average markup figures. The procedure we use, however, has the advantage that first computing the markup ratios and then averaging them over time (instead of first averaging them over time and then computing the markup ratios) makes it possible to explore the time series variability in each individual markup series and perhaps also to provide some measure of over-time variability associated with the markup.

Finally, we have taken the above-calculated average markup figures for each product pair and computed the average markup for each of the nineteen product categories included in our sample. As before, these category averages were also calculated as weighted averages. However, unlike the previous steps, here the weighing was done according to the share of the $d o l$ lar value of the sales for each product pair in the dollar value of the total sales in the category. For example, if in the analgesics category we have twenty-four national brand/private-label product pairs, to compute the category average markup, we took the markup figures for the twenty-four product pairs (listed in table 7A.5) and computed their weighted average, where the weights are the ratios of the total dollar sales of the pair to the total dollar sales in the category. The weights here use dollar sales rather than unit sales in order to avoid the problem of "adding apples to oranges." The resulting category averages figures are reported in figures 7.1-7.6 and in the bottom rows of tables 7A.1-7A.19.

Along with the average markup ratio measures we also report their in- 
terquartile ranges. The interquartile range figures reported for individual product pairs within each category (tables 7A.1-7A.19) are computed by using the weekly time series of the corresponding markup ratios and determining the range in which 50 percent of these weekly markups fall for each product pair. The interquartile range figures reported for category averages (see the bottom rows in tables 7A.1-7A.19) are computed by considering the average weekly markups for each product pair and determining the range in which 50 percent of them fall for each category.

In the individual category tables (tables 7A.1-7A.19), we identify each national brand/private-label product pair by the name of the branded products because the private-label equivalents of the nationally branded products listed in these tables are always the Dominick's store brand products. Note also that in these tables some brand names appear more than once. This is because they refer to different sizes. For example, in the analgesics category reported in table 7A.5, Advil (with the corresponding private-label product) is listed three times because it comes in three different sizes ("counts" or number of tablets): 10, 50, and 100.

\subsection{Empirical Findings}

In this section we report computations of the five markup ratios derived in section 7.2.3. Our primary objective is to offer the tightest possible lower bound on $\mu^{*}$, the "ideal" full markup ratio for the nationally branded product. Our second goal is to provide a sense of the quantitative relationships between the five markup ratios that we derived in section 7.2.3. These ratios offer insight into the anatomy of $\hat{\mu}$; and because they have interpretations as markups at specific stages of the production and distribution processes, they are of interest in their own right.

In section 7.5.1, we report the results for category averages. We begin with the "bottom line," the "preferred" measure $\hat{\mu}$, our tightest lower bound on $\mu^{*}$. We then move on to $\mu^{w}$, the ratio of the wholesale prices, which usually exceeds $\hat{\mu}$ and is a lower bound on the manufacturer's markup. Next, we discuss $\mu_{b}$ and $\mu_{g}$, the retailer's markups over wholesale price for branded and private-label products, respectively. These provide the link from $\mu^{w}$ to the more commonly observed markup ratio computed using retail prices, $\mu^{r}$, which is the last of the five ratios that we report. Finally, we close the section with the presentation of a graph that shows $\hat{\mu}$ flanked by $\mu^{w}$ and $\mu^{r}$ and thus offers an empirical counterpart to the bounding inequalities derived in section 7.2.3.

In section 7.5.2 we focus in more detail on selected product categories. The category of ready-to-eat breakfast cereals, in particular, has been the object of several studies in the econometric literature, and we are able to compare our results with available structural estimates. Finally, examining 
closely several product pairs in representative categories, we obtain some insight into within-category variation of the markups.

\subsubsection{Results for Category Averages}

\section{The "Preferred" Lower-bound Markup Measure $\hat{\mu}$}

In figure 7.1 we report our "preferred" lower-bound markup measure labeled $\hat{\mu}$ in section 7.2.3. The figure shows that in four product categories-

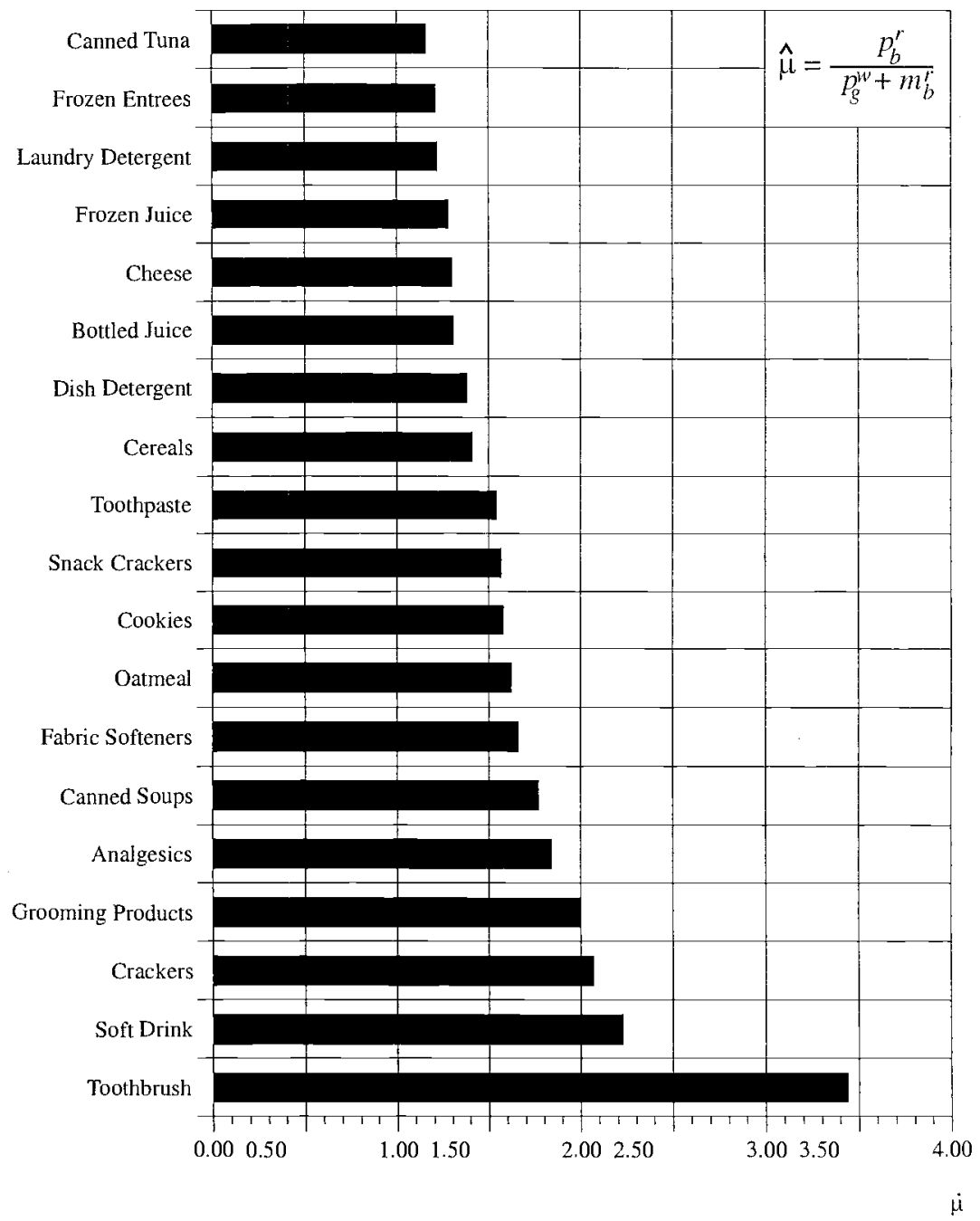

Fig. 7.1 Markup Ratio for Branded Products: "Preferred" Lower Bound (Measure a) 
toothbrushes, soft drinks, crackers, and grooming products-the mean lower-bound markup ratio $\hat{\mu}$ is on the order of 2.0 or higher. In three categories - analgesics, canned soups, and fabric softeners $-\hat{\mu}$ averages between 1.60 and 2.00, whereas in six categories - oatmeal, cookies, snack crackers, toothpaste, cereals, and dish detergent-mean $\hat{\mu}$ falls approximately in the range 1.40-1.60. For the remaining six categories-bottled juice, cheese, frozen juice, laundry detergents, frozen entrees, and canned tuna-the average lower-bound markup ratio is less than 1.40 . The categories with smallest $\hat{\mu}$ are canned tuna (1.16), frozen entrees (1.21), and laundry detergents (1.22).

Figure 7.1 provides a good deal of evidence that nationally branded products are sold at a substantial markup. In more than half of the categories, the average lower-bound on the markup ratio is at least 1.40. Since the measure we report here is conservative, true markup ratios are likely to be even higher.

\section{Manufacturer's Markup: Lower Bound Based on Wholesale Prices}

As discussed in sections 7.2 and 7.3, $\mu^{w}$ - the ratio of the wholesale prices - provides a lower bound for the brand manufacturer's markup. In figure 7.2 we present average $\mu^{w}$ by category along with our preferred lower bound, $\hat{\mu}$. A comparison of the two lower-bound measures indicates that with the exception of the toothbrush and crackers categories, the two markup ratios, $\mu^{w}$ and $\hat{\mu}$, are of similar magnitude. For ten categories-fabric softeners, oatmeal, toothpaste, cereal, dish detergent, bottled juice, cheese, laundry detergent, frozen entrees, and canned tuna - the difference between the two measures is less than 0.1. For seven categories-soft drinks, grooming products, analgesics, canned soups, cookies, snack crackers, and frozen juice- the difference between the two measures is between 0.10 and 0.20 . Nationally branded products that have a large manufacturer's markup according to $\mu^{w}$ also have large full markups according to $\hat{\mu}$. This should not be surprising, as we obtained $\hat{\mu}$ from $\mu^{w}$ by adding $m_{b}^{r}$ - the retailer's margin on the brand - to both the numerator and the denominator of $\mu^{w}$, and as we show immediately below, with a few exceptions, the retail margins on branded products are quite small. This conclusion also holds, for the most part, within individual categories, as tables 7A.1-7A.19 indicate.

As we move down the list to categories with lower markup ratios, the gap between the two markup measures becomes particularly small, a direct result of the algebraic relationship between $\hat{\mu}$ and $\mu^{w}$. Thus, although the conservative treatment of the retailer's handling cost embodied in $\hat{\mu}$ is theoretically appealing, its actual quantitative significance is not overwhelming.

\section{Retailer's Markups on Private Labels and National Brands}

In figure 7.3 we report the retailer's markup - the ratio of retail price to wholesale price - for the private-label $\left(\mu_{g}\right)$ and nationally branded products 


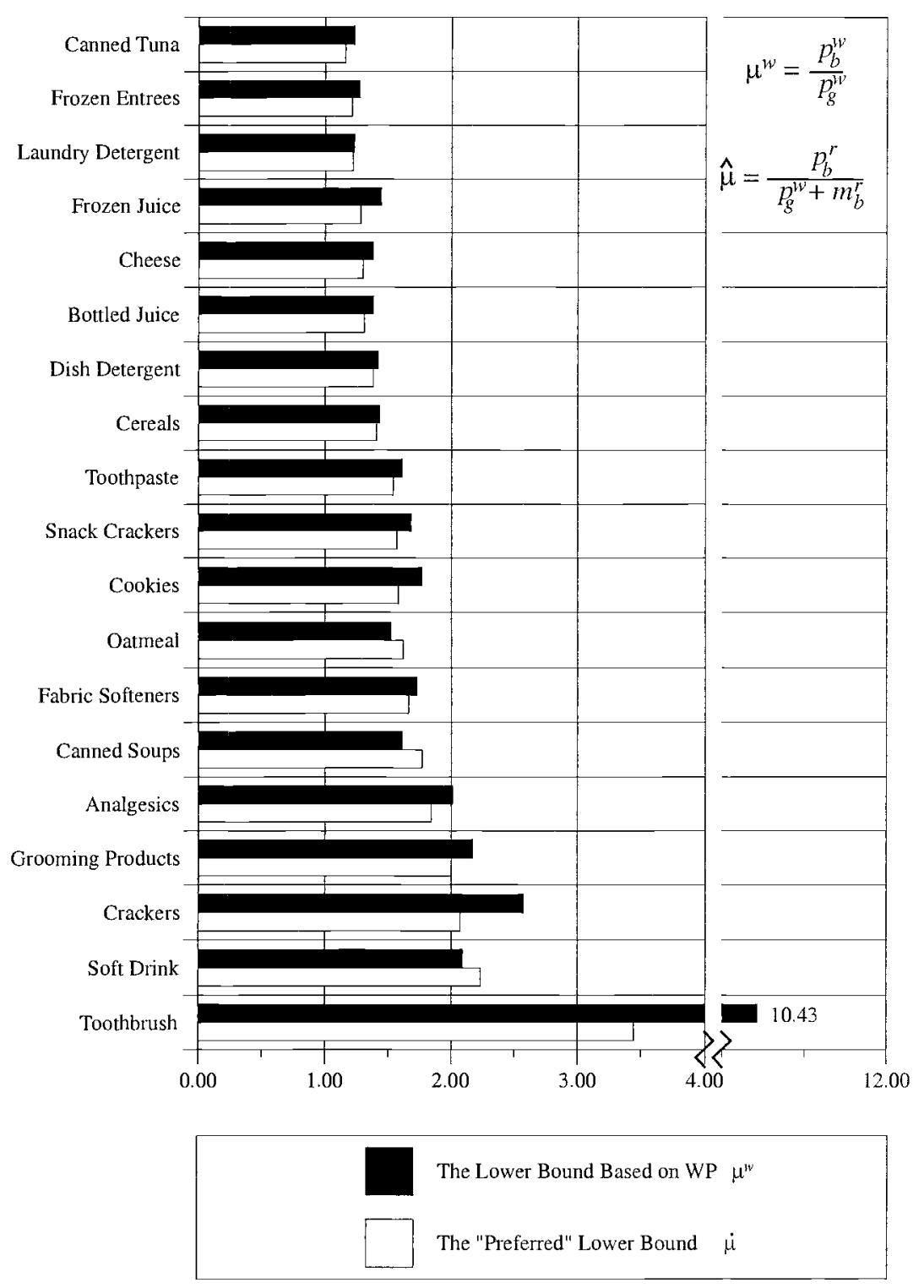

Fig. 7.2 National Brand Markup: The Preferred" Lower Bound (Measure a) vs. the Lower Bound Based on Wholesale Prices (Measure c) 


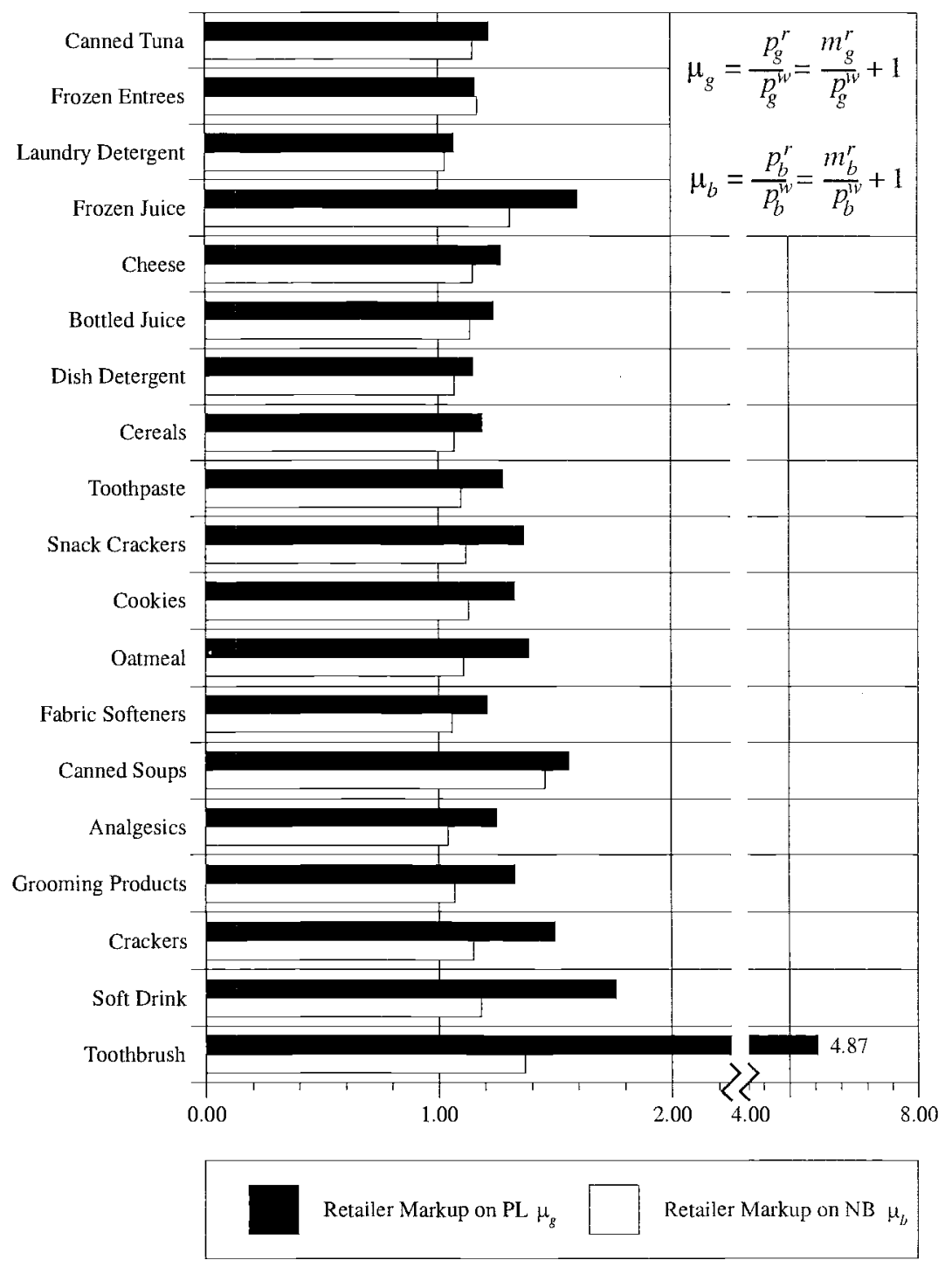

Fig. 7.3 Retailer's Markup Ratio on National Brand (Measure d) and Private Lavel (Measure e)

$\left(\mu_{b}\right)$, by category. According to the figure, for all but three products, the retailer's markup ratios for the nationally branded products are all less than 1.20. The exceptions are canned soups (1.46), toothbrushes (1.37), and frozen juice (1.31). Moreover, the retailer's markups on nationally branded products are small both in comparison to $\hat{\mu}$ and $\mu^{w}$ (see figure 7.4 for a comparison of $\mu_{b}$ with $\mu^{w}$ ) and in comparison to retailer's markup on the private 


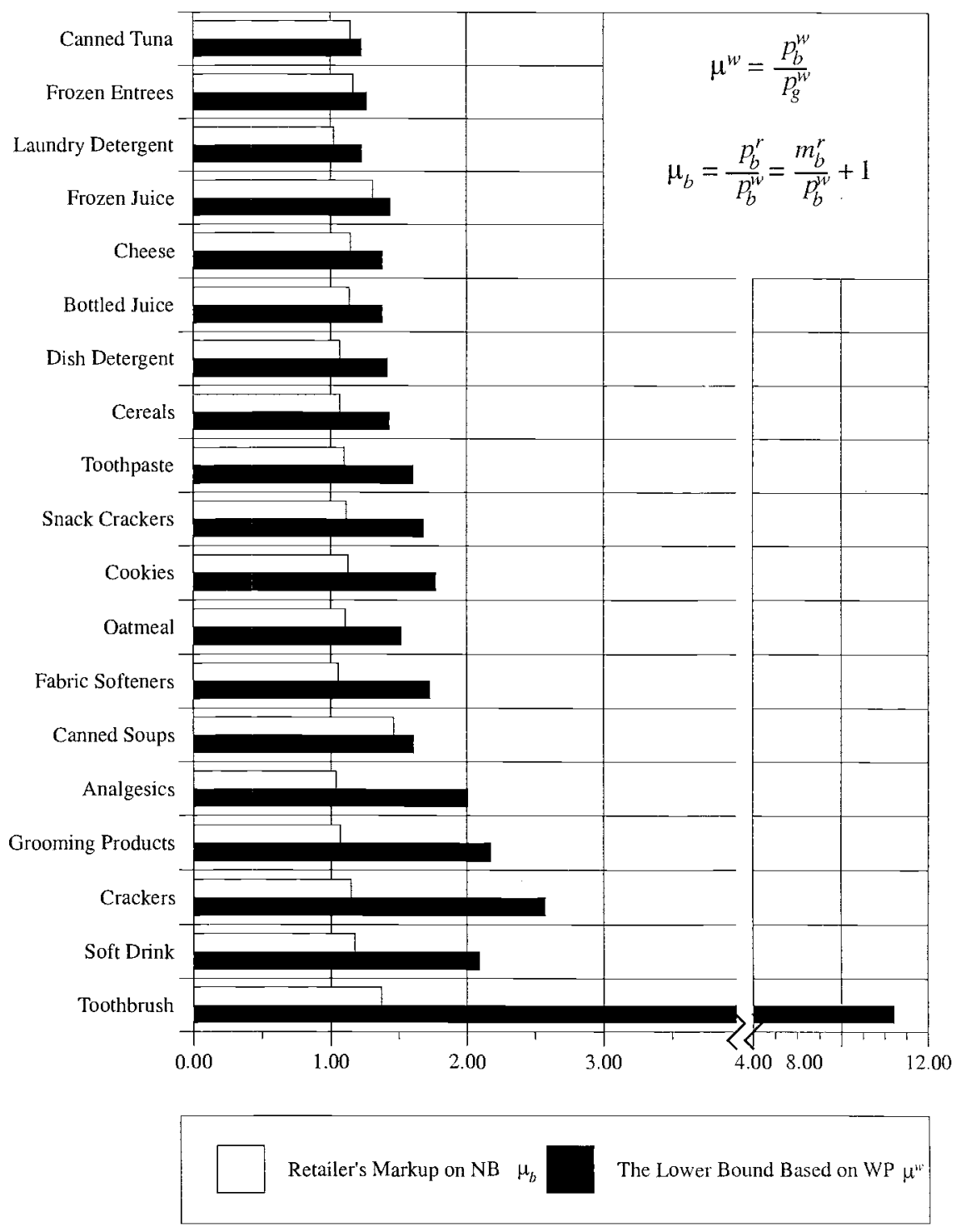

Fig. 7.4 The Lower Bound Markup Based on Wholesale Prices (Measure c) vs. Retailer's Markup on NB (Measure d)

label. Specifically, in all but one category (frozen entrees), retail markups are higher for private labels than for national brands. Second, in all but one category (frozen juice), the retail markups for nationally branded products are lower than the manufacturers' markups.

According to figure 7.3 , the retailer's markup ratios for nationally 
branded products range from 1.03 for laundry detergent to 1.46 for canned soups. For more than one-third of categories - grooming products, analgesics, fabric softeners, toothpaste, cereal, dish detergents, and laundry detergents - the average retailer's markup ratio on the brand is less than 1.10.

In contrast, the retailer's markup ratios for private-label products are substantially higher. Omitting the puzzling case of the toothbrush category (with a measured retailer's markup ratio of 4.87), the average retailer's markup on the private-label version ranges from 1.07 for laundry detergents to 1.76 for soft drinks. Only in the categories of laundry detergents, dish detergents, cereals, and frozen entrees are the retailer's private-label markup ratios less than 1.20 .

Thus we find clear evidence that retailers' markups are higher for private labels than national brands. This fact is well known in the trade. For example, according to Morton and Zettelmeyer (2000), retailers "achieve higher price-cost margins [on private-label products] than those earned with national brands. Industry observers, the popular press and academic work all indicate that this effect can be quite large." According to Hoch and Banerji (1993), "Industry sources suggest that retailer gross margins on private labels are $20 \%$ to $30 \%$ higher than on national brands." This divergence between retailers' margins on branded and private-label products is associated with differences between the profitability of American and European supermarkets. "In European supermarkets, higher private-label sales result in higher average pretax profits. U.S. supermarkets average only $15 \%$ of sales from private labels, they average $2 \%$ pretax profits from all sales. By contrast, European grocery stores such as Sainsbury's, with 54\% of its sales coming from private labels, and Tesco, with $41 \%$, average $7 \%$ pretax profits" (Quelch and Harding 1996).

\section{Lower-Bound Measure of the Full Markup Based on Retail Prices}

Previous authors, such as Scherer (1980), Carlton and Perloff (1994), and Nevo (2001), have focused on the ratio of retail prices $\mu^{r}$. Although we have made the case that $\hat{\mu}$ is a better measure than $\mu^{r}$ of the markup paid by consumers over full marginal cost, it is useful to report $\mu^{r}$ as well, both for comparison with these previous studies and because retail prices are becoming increasingly available with the development of new technologies in computers, electronic scanners, and the like.

Figure 7.5 shows the markup ratios for national brands based on the retail prices of nationally branded products and private labels, $\mu^{r}$, along with our preferred lower bound, $\hat{\mu}$. The markup ratio figures computing using the retail prices range from a high of 2.33 for toothbrushes to a low of 1.14 for canned tuna. The majority of the markups are below 1.4, the only exceptions being crackers (2.00), grooming products (1.75), analgesics (1.63), fabric softeners (1.52), and cookies (1.49), as well as the aforementioned 


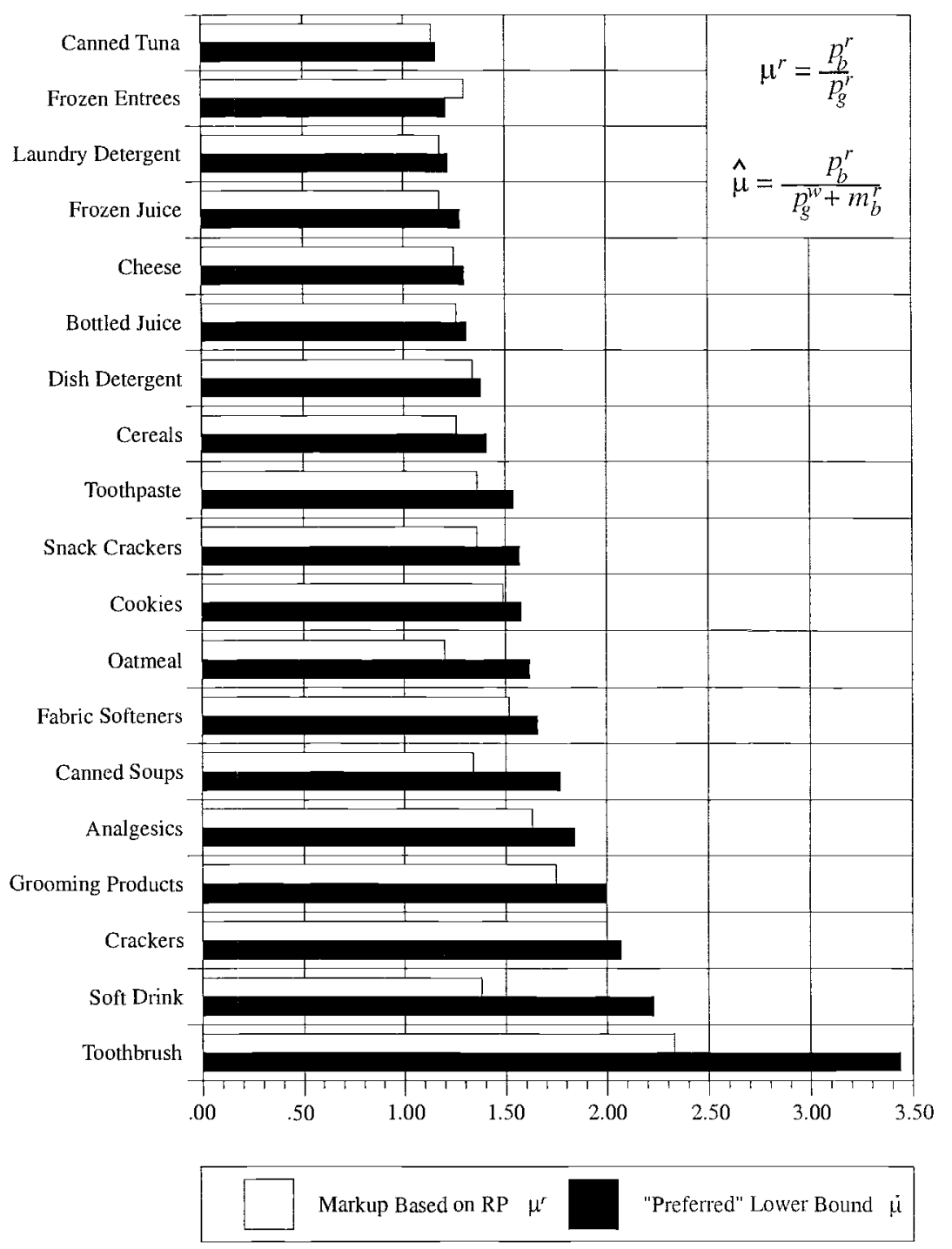

Fig. 7.5 National Brand Markup: The "Preferred" Lower Bound (Measure a) vs. the Lower Bound Measure Based on Retail Price (Measure b)

toothbrushes (2.33). This is in general true within the individual categories as well, again with the exception of the above categories. Recall that $\mu^{r}$ underestimates the full markup to a greater extent than does $\hat{\mu}$, because $\mu^{r}$ treats the handling cost more conservatively by using as its proxy the retailer's margin on the private-label product. 


\section{Summary}

To further explore the relationship between our preferred lower-bound ratio and the lower-bound ratios computed using the wholesale and the retail prices, we plot the three lower-bound series together in figure 7.6. As the figure demonstrates, the lower-bound ratio calculated using the wholesale price usually exceeds our "preferred" lower bound, whereas the lowerbound ratio calculated using the retail price typically falls below the pre-

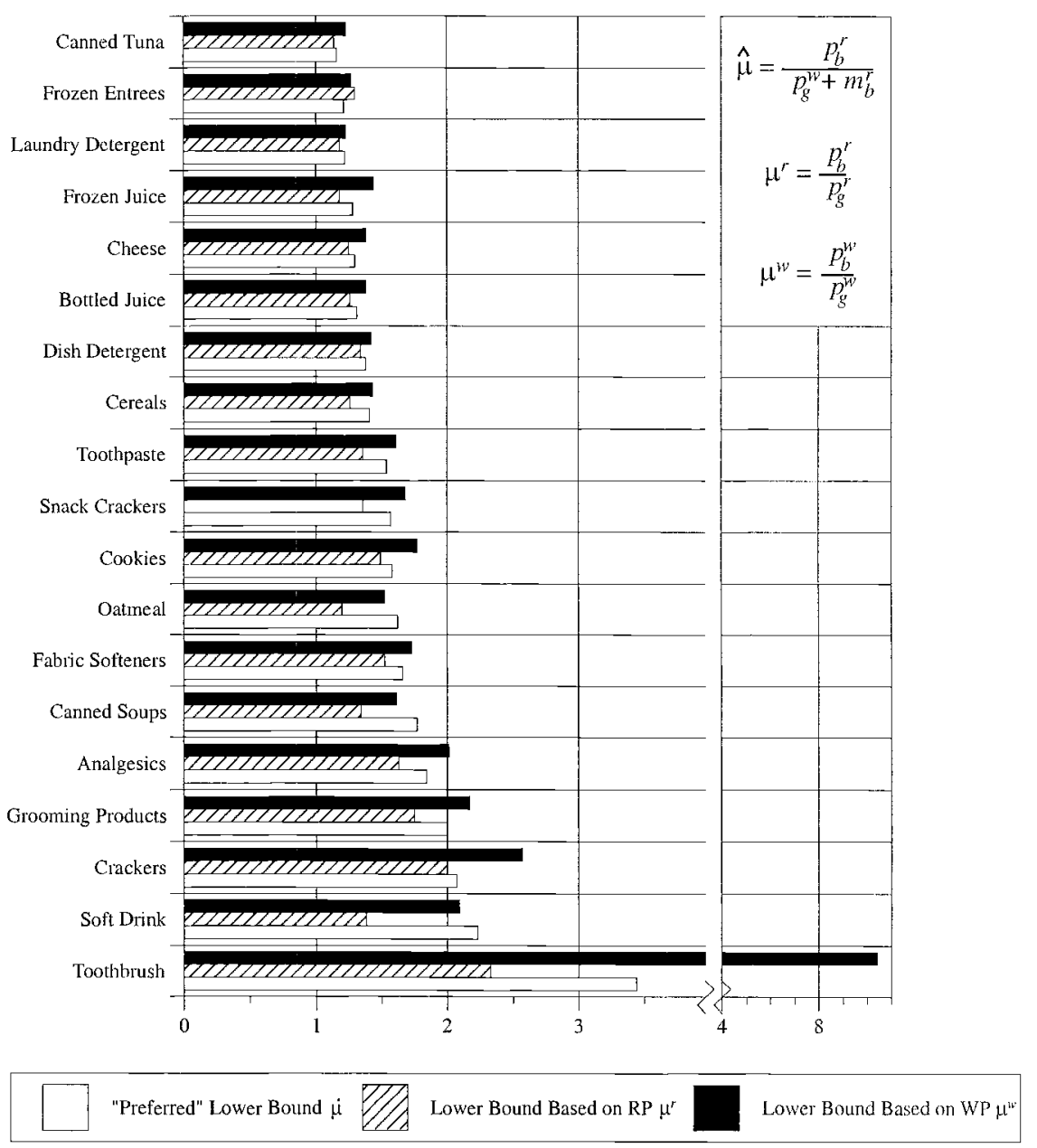

Fig. 7.6 Lower Bounds on the National Brand Manufacturers' Markup Ratio: The "Preferred" Lower Bound (Measure a), the Lower Bound Based on Wholesale Price (Measure c), and the Lower Bound Based on Retail Price (Measure b) 
ferred lower bound. The figure also indicates that the three lower-bound measures attain values that are closer to each other as the markups' size decreases.

\subsubsection{Detailed Results for Some Selected Categories and Products}

In tables 7A.1-7A.19, we report detailed tabulations of all five markup ratios derived in section 7.2.3, for each national brand/private-label pair for all nineteen product categories included in our data set.

Among the nineteen categories, the toothbrush category (table 7A.1) attains the highest average value of our preferred lower-bound markup ratio, with a category average of 3.44. Within the category, four types of Crest toothbrush (of different size and strength) attain a markup ratio in the range of 5.48-5.80, and two types of Reach toothbrush attain markup values of 4.36 and 4.56 . The results for the remaining products in this category suggest more moderate market power, with markup ratios in the range of 1.56 for Johnson and Johnson waxed mint dental floss and 1.49 for the Pepsodent toothbrush.

The manufacturers' lower-bound markup ratios calculated using the wholesale prices attain even higher values. For example, for the four Crest and two Reach toothbrushes, $\mu^{w}$ falls in the range of 13.00-19.84. Overall, the category average of these markup figures is 10.43 . The reasons for these very high measured markup figures, unique to the toothbrush category, remain a mystery.

The figures in the last two columns of table 7A.1 suggest that the retailer's markup on private-label products in this category far exceeds its markup ratio on the corresponding nationally branded product by nearly an order of magnitude. For example, for the highest markup brand, the Crest toothbrush, the retailer's markup ratio is only 1.14, whereas the markup ratio on the corresponding private label is 7.03. Overall, the retailer's average markup ratio for nationally branded products in this category equals 1.37 , whereas the average markup ratio for private-label products equals 4.87 .

Finally, the lower-bound markup ratios calculated using the retail prices are more moderate, although for the top four products the ratio still exceeds 3.00 , and for another two products it is close to 3.00 . The category average for this ratio is 2.33 .

For the remaining eighteen categories we find more moderate markup figures. Nevertheless, in most categories they are quite substantial. For example, for the analgesics category, reported in table 7A.5, the average of our preferred lower-bound markup ratio is 1.84 . Several products in this category have especially high markup ratios. For example, the preferred lower bound on the markup ratio for children's Anacin-3 tablets is 4.99 (column [1]). Four other products with especially high markup ratios are Panadol children's tablets, with the lower-bound markup ratio of 3.91, followed by 
Tylenol extra- strength caplets, with 2.53; Tylenol tablets (regular), with 2.44; and Bayer children's aspirin, with a markup ratio of 2.28. ${ }^{10}$

Turning to the manufacturers' markup ratios calculated using the wholesale prices (column [2]), we find that they are quantitatively very similar to the values of $\hat{\mu}$, with the exception of children's Anacin-3 tablets, with a manufacturer's lower-bound markup ratio of 7.62, and Panadol children's tablets, with a manufacturer's lower-bound markup ratio of 6.73. Further, as we move down the list from the highest preferred lower bound to the lowest, the discrepancy between the two ratios essentially disappears, as expected. Overall, the lower-bound manufacturers' markup ratios calculated using wholesale prices are high. For example, the figures in the table indicate that for seven of the twenty-four products in this category, the manufacturers' lower-bound markup ratio exceeds 2.00, and for another ten products the ratio exceeds 1.7. Only for two products, both Tylenol extrastrength tablets (different sizes), is $\mu^{w}$ below 1.2. Overall, the average manufacturer's lower-bound markup ratio for this category equals 2.01.

The figures in the third column of table 7A.5, which measure the lower bound on the full markup using retail prices, are smaller than the first two ratios, as predicted by the inequalities derived in section 7.2.3. Still, the markup ratios we obtain for the analgesics category are large. For example, of the twenty-four products, for three products - children's Anacin-3 tablets, Panadol children's tablets, and Tylenol extra-strength caplets - the markup ratio calculated using only the retail prices exceeds 2.0 ; for ten other products the ratio exceeds 1.6 , and for another eight products the markup ratio exceeds 1.3. The average markup ratio using retail prices for the analgesics category equals 1.63 .

Finally, the retailer's markup on the national brand systematically exceeds its markup on the private label. For example, for twenty-three of the twenty-four products (Bayer children's aspirin being the only exception), the retailer's markup on nationally branded products in this category is less than 1.15 , with an overall average of only 1.04. In contrast, the markup ratio on the private label is substantially higher, averaging 1.25 .

Next, consider the cereals category. According to table 7A.12, all of the markup figures we find in this category are smaller than those we reported for the analgesics category. As the figures in the first column of the table suggest, here the preferred lower-bound markup ratio falls in the range 1.271.57 , with an average of 1.41 , again suggestive of very substantial market power. Total raisin bran attains the highest lower-bound value with 1.57, followed by Kellogg's corn flakes, with 1.54, and Post raisin bran and Kellogg's Nut \& Honey, each with a lower-bound markup ratio of 1.41 .

The manufacturers' markup figures reported in the second column of

10. Ernie Berndt noted that the extraordinarily high markups on children's medicine might possibly be explained by parents' risk aversion regarding their children's health. 
table 7A.12 are only slightly higher than the preferred lower-bound figures. For example, for Total raisin bran, the lower bound on the manufacturer's markup ratio equals 1.61, in comparison to the preferred lower bound of 1.57. The manufacturers' markup and the preferred markup figures are equally close for the remaining products of the category. Overall, cereal manufacturers on average mark up their branded product prices to 1.43 of their marginal cost.

According to the third column of table 7A.12, the markup ratios we obtain using retail prices average 1.26 for the cereals category. Total raisin bran still attains the highest value with 1.46, and Kellogg's corn flakes' markup ratio is a distant second with a value of 1.23. Finally, comparing the retailer's markup ratio on branded products to its markup ratio on private labels, we again find that the latter, 1.19 on average, exceeds the former, 1.07 on average.

It is instructive to compare our markup figures in this category to existing econometric estimates. The category of breakfast cereals has been a subject of several recent studies, such as those by Hausman (1997) and Nevo (2001). Nevo presents estimates of price-marginal cost margins under different assumptions on market structure and finds that they range from about 1.3 to as high as 2.0 , very much consistent with the lower-bound measures reported here.

As a final example, consider the crackers category, in which we were able to find ten matching pairs of national brand and private-label products. According to table 7A.3, our preferred lower-bound markup figures are relatively high, with the highest ratio for Nabisco premium saltines (2.84), and the lowest for Salerno graham crackers (1.34); the overall category average is 2.07. For four branded products, two Nabisco Premium saltines (different sizes) and two Salerno saltines (also different sizes), the ratio exceeds 2.00. Only for two products is the lower-bound markup ratio less than 1.40.

The manufacturers' lower-bound markup ratios (second column of table 7A.3) substantially exceed the preferred lower-bound figures. For example, the category average of the manufacturers' lower-bound markup equals 2.57 , which is about 25 percent higher than the preferred lower bound. Further, for Nabisco Premium saltines, the manufacturer's lower-bound markup ratio is 4.22 , about 50 percent higher than the corresponding preferred lower bound.

It turns out that in the crackers category we obtain especially high markup figures even if we consider the lower bound on the full markup ratio calculated using only the retail prices. For example, according to table 7A.3 (column [3]), the category average of this markup ratio is 2.00 , which is the second highest (the toothbrush category being first) among all nineteen categories included in our study. Individual product markup ratios calculated using the retail prices range from the highest ratio of 3.12 for Nabisco premium saltines to 1.20 for Salerno graham crackers. 
Finally, if we consider the retailer's markup on the nationally branded and private-label products, we find that, as before, the retailer's markup on the private label is systematically higher than its markup on the nationally branded product, with an average of 1.50 in contrast to 1.15 , a difference of about 20 percent. ${ }^{11}$

Next, consider some specific products that stand out in other categories. In the canned soup category (table 7A.6), the only nationally branded product with a preferred lower-bound markup ratio in excess of 2.00 is Campbell's tomato soup, with a ratio of 2.61. The remaining products in this category attain a markup value of less than 2.00. In the cookies category (table 7A.9), two brand-name products, Nutter Butter peanut butter and Cameo crème sandwich, attain a "preferred" lower-bound markup ratio of about 2.70 , and another ten products attain markup values exceeding 1.40 . In the snack cracker category (table 7A.10), Nabisco Ritz cracker attains the highest preferred lower-bound markup ratio, 1.74, followed by Nabisco Ritz Bits, with a ratio of 1.58 .

In the soft drinks category (table 7A.2), we find that Coca-Cola Classic and Pepsi cola attain preferred lower-bound markup values of 3.83 and 2.36 , respectively. Other branded products with particularly high lowerbound markup ratios in the soft drink category are Schweppes ginger ale, with 3.52; Snapple strawberry and Snapple pink lemonade, with 2.88 and 2.47, respectively; Diet Pepsi, with 2.28; and Seagrams ginger ale, with 2.18. Diet Coke attains a more moderate lower-bound markup ratio of 1.69.

Finally, the nationally branded products attaining the highest preferred lower-bound markup ratios in the remaining categories include Motts apple juice in the bottled juice category, Minute Maid pink lemonade in the frozen juice category, Crest Regular in the toothpaste category, Kraft soft Philly cream cheese in the cheese category, Dawn lemon in the dish detergent category, L.C. Baked cheese ravioli in the frozen entrees category, Bounce single scented in the fabric softener category, Trac II Plus cart 10 in the grooming products category, ultra Ivory Snow in the laundry detergent category, quick Quaker oats in the oatmeal category, and Chicken of the Sea lite tuna in water in the canned tuna category.

\subsection{The Role of the Materials Share}

It might be worthwhile to hypothesize as to the determinants of crosscategory and within-category variation in the magnitude of markup ratios. Consider first the within-category variation. In most categories, we find

11. Slade (1998) assumes a 20 percent retail markup for saltine crackers in her study of price adjustment costs at several Pennsylvania grocery stores. This is equivalent to a retailer's markup ratio of 1.20 . The average retailer's markup ratio on the nationally branded product we report is 1.15 , with the interquartile range of $(1.12-1.17)$ indeed very close to what Slade assumes. 
that more heavily branded and well-known products achieve higher markups. For example, Kellogg's corn flakes, Nabisco Premium saltine crackers, Crest toothpaste, Coca-Cola Classic, Motts apple juice, Nutter Butter peanut butter, Nabisco Ritz crackers, Kraft cream cheese, Dawn lemon dish detergent, Bounce single scented fabric softener, and so on, which have the highest markups within respective categories, all are heavily advertised and widely recognized nationally branded products.

Perhaps a more interesting issue is the variation in markup ratios across product categories. Basu and Fernald (1997) and Rotemberg and Woodford (1996) provide the following formula linking the gross output markups that are the focus of this paper to the value added markups, via products material share:

$$
\mu^{v}=\frac{\mu(1-s)}{1-\mu s},
$$

where $\mu^{v}$ denotes the markup on real value added, $s$ denotes the intermediate inputs share in total revenue, and $\mu$ denotes the gross output markup. The formula implies that if the value added markup is to be finite, the gross output markup must not exceed $1 / s$.

Nevo (2001), using data from the Annual Survey of Manufacturers over the period 1988-92, provides materials share figures for ready-to-eat cereals (SIC [Standard Industrial Classification] 2043) and for the food industry overall (SIC 20). For cereals, he reports a materials share of 26.5 percent, which from the above formula implies that the gross output markup should not exceed $1 / 0.265=3.77$. Indeed, according to our findings (see figure 7.1), the preferred lower-bound markup ratio for the cereals category equals 1.41, well below the upper bound imposed by the above formula.

For the entire food industry, Nevo reports a materials share of 63.4 percent. This imposes an upper bound of 1.58 on the gross output markup ratio. Twelve of the nineteen categories we study would be classified as food. These are soft drinks, crackers, canned soups, oatmeal, cookies, snack crackers, cereals, bottled juice, cheese, frozen juice, frozen entrees, and canned tuna. Of these twelve categories, the numerical values of the preferred markup ratios for the last eight categories fall below 1.58. For two additional categories (oatmeal and canned soups), the markup ratio is only slightly higher than 1.58. For only two categories (crackers and soft drinks) does the markup ratio substantially exceed 1.58 . This suggests that materials share in these two categories must be smaller than 26.5 percent, which seems reasonable. Moreover, the interquartile ranges we report indicate that the great majority of the products in each one of the twelve categories satisfy this constraint.

Finally, without having actual data on the cost shares of intermediate inputs used by manufacturers of individual food categories, we strongly suspect that the products with the lowest markup ratios, such as canned tuna, 
frozen entrees, cheese, frozen juice, and bottled juice, also have the highest share of materials. ${ }^{12}$

\subsection{Concluding Remarks}

In this paper we study the size of markups for nationally branded products sold in a large U.S. retail supermarket chain. Our approach, which we hope will serve as a complement to more structural econometric approaches, treats the wholesale price of a comparable private-label product as an upper bound on the marginal costs faced by the brand manufacturer. Using scanner data from a large Midwestern chain, we have computed various upper- and lower-bound markup ratios for over 230 products in nineteen categories. We found that markup ratios measured this way range from 3.44 for toothbrushes and 2.23 for soft drinks to about 1.15-1.20 for canned tuna and frozen entrees, with the majority of categories falling in the range 1.40-2.10. Lower bounds on manufacturers' markups are even higher. Thus, the data indicate that markups on nationally branded products sold in U.S. supermarkets are large.

Our approach offers several benefits. Because it involves only a simple computation (once the data have been assembled), the method permits calculation of markups for a large variety of products. It is transparent and intuitive, and it offers a benchmark comparison for more structural approaches.

Particularly in light of the importance of markups in recent macroeconomic discourse, one might ask whether the finding of high markups for heavily advertised differentiated products generalizes to the economy at large. In this direction, it is worth noting that many "commodity" products such as automotive parts, personal computers and their components, and many other producers' goods come in both branded and nonbranded (OEM or Original Equipment Manufacturer) versions, and that the price gap for those products is comparable to that for the supermarket goods we have studied. This is also true for other consumer goods sold outside the supermarket industry, home and office supply products being one example.

\section{Appendix}

In this appendix we present detailed results for each pair of national brand and private-label products, for each of the nineteen product categories in-

12. We are grateful to Susanto Basu for calling our attention to the above formula and its implications. 
cluded in our data set. The results are reported in separate tables, tables 7A.1 through 7A.19, by categories.

In these tables, columns (1)-(5) correspond to the five markup measures we report in the paper, as follows:

1. Column (1) corresponds to the markup measure (a), $\hat{\mu}$, which is our "preferred" lower bound on the full markup.

2. Column (2) corresponds to the markup measure (c), $\mu^{w}$, which provides a lower bound on manufacturers' markup by using wholesale prices.

3. Column (3) corresponds to the markup measure (b), $\mu^{r}$, which provides a lower bound on the full markup by using retail prices.

4. Column (4) corresponds to the markup measure (d), $\mu_{b}$, which is the retailer's markup on the nationally branded product.

5. Column (5) corresponds to the markup measure (e), $\mu_{g}$, which measures the retailer's markup on private label product.

In each table, the figures in parentheses indicate the interquartile range. The sample size numbers, which are listed in the last column of each table, report the number of weekly time series observations of price and cost data used in calculating the various markup measures for the corresponding national brand/private-label product pair. See text for more details. 


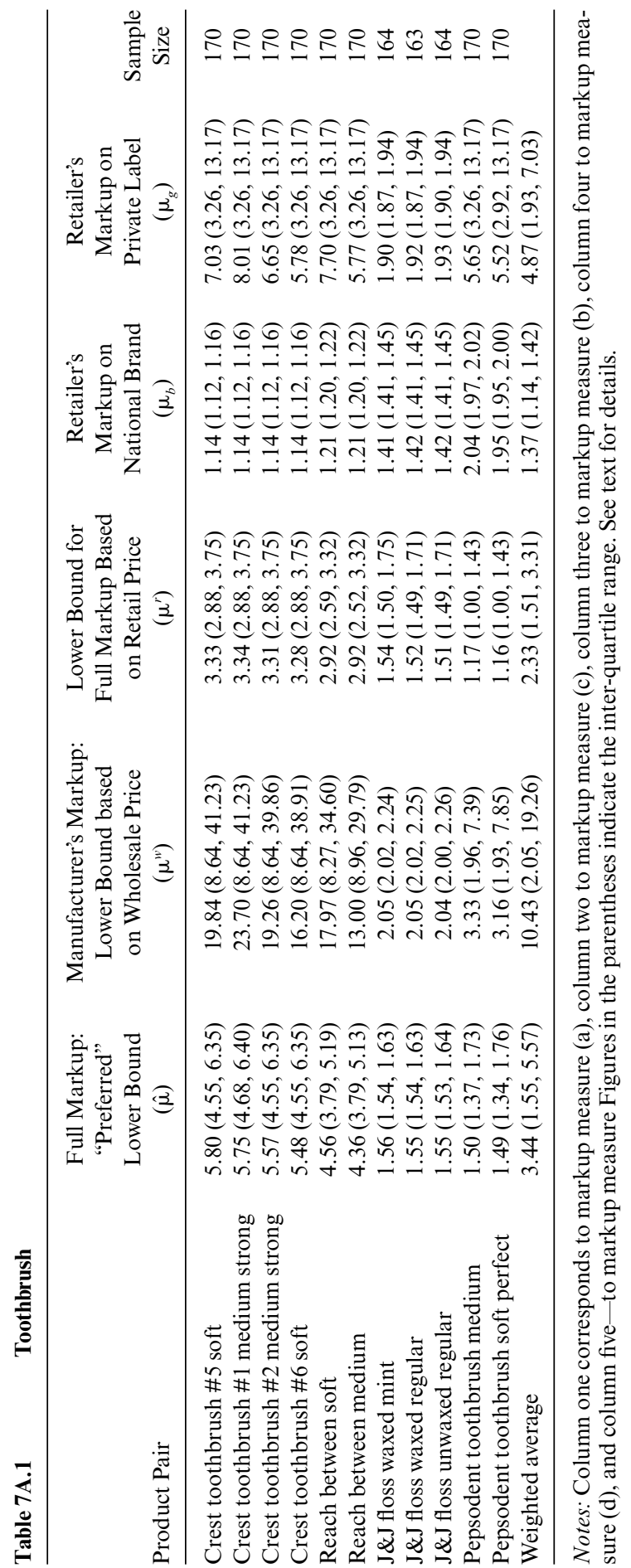




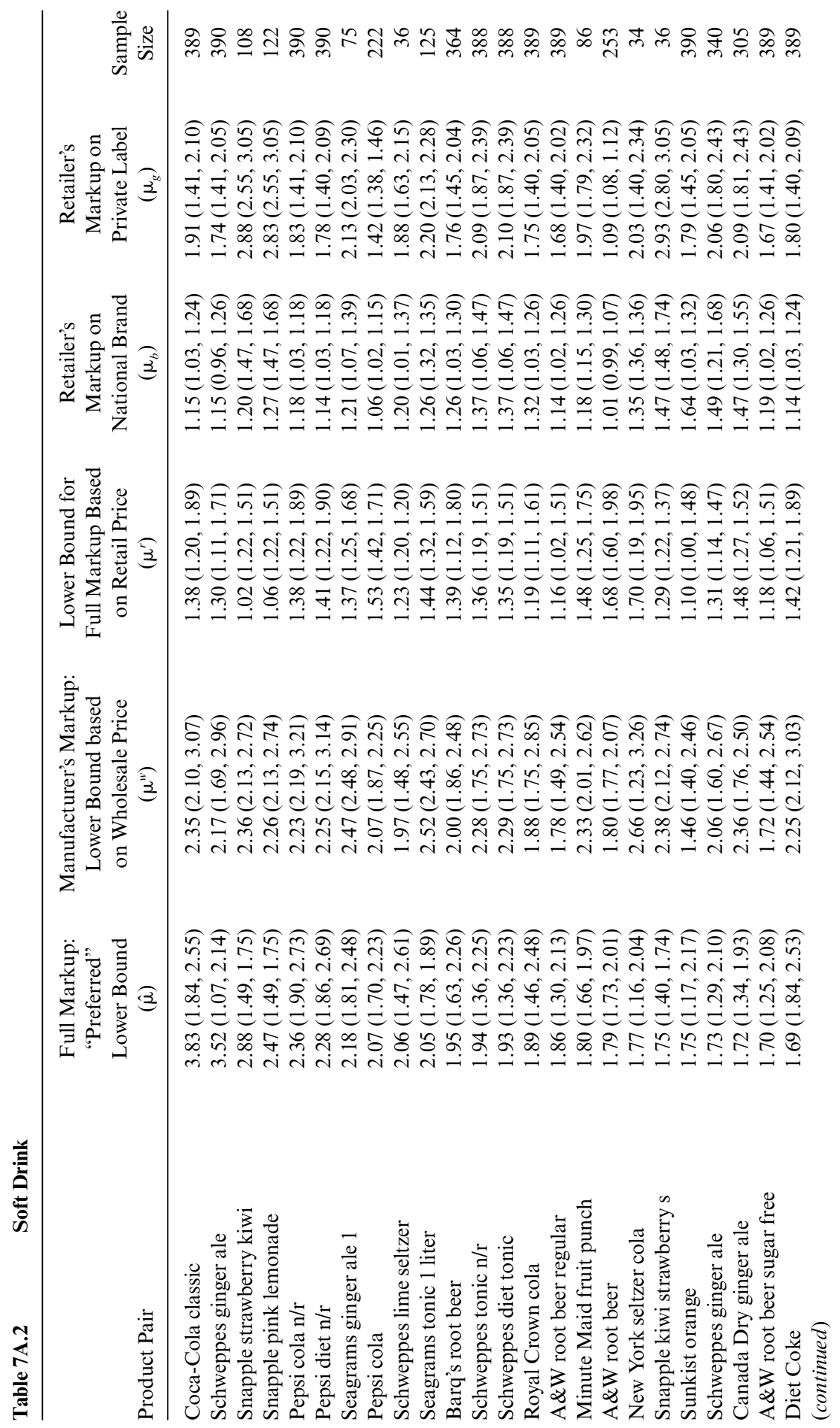




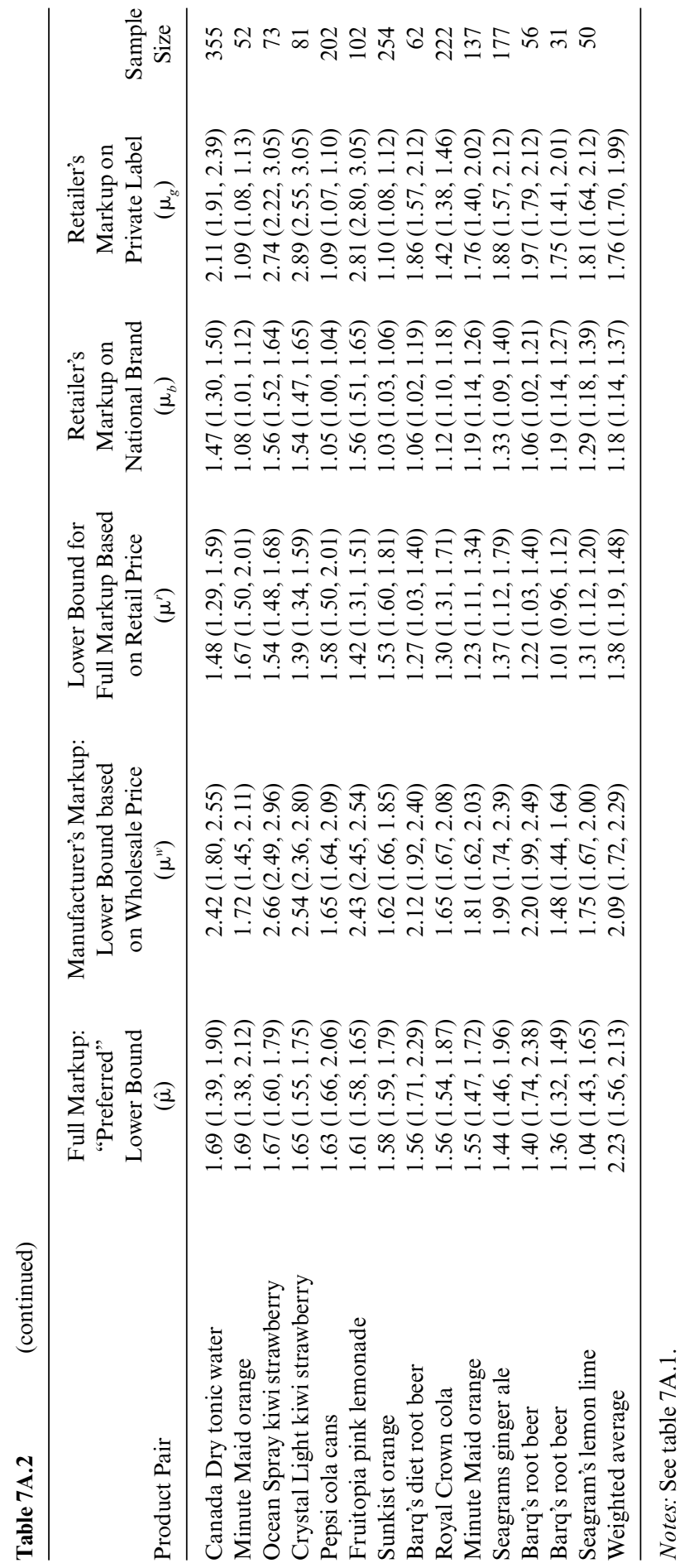




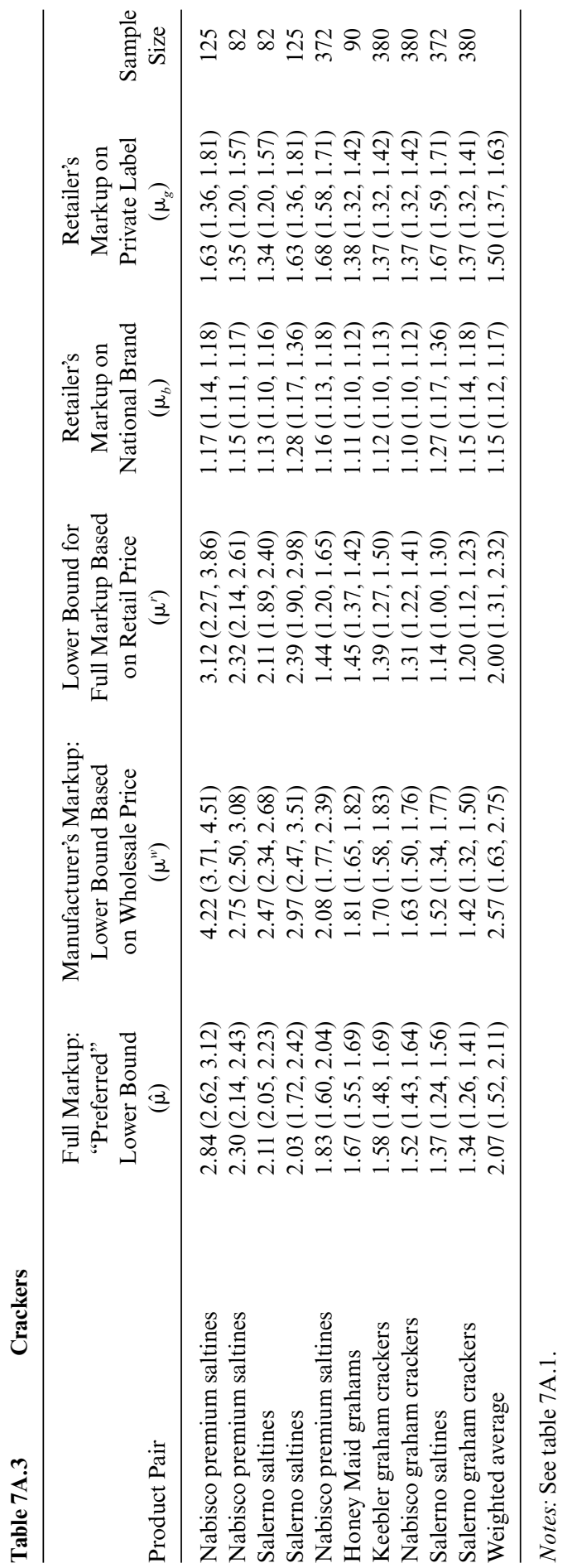




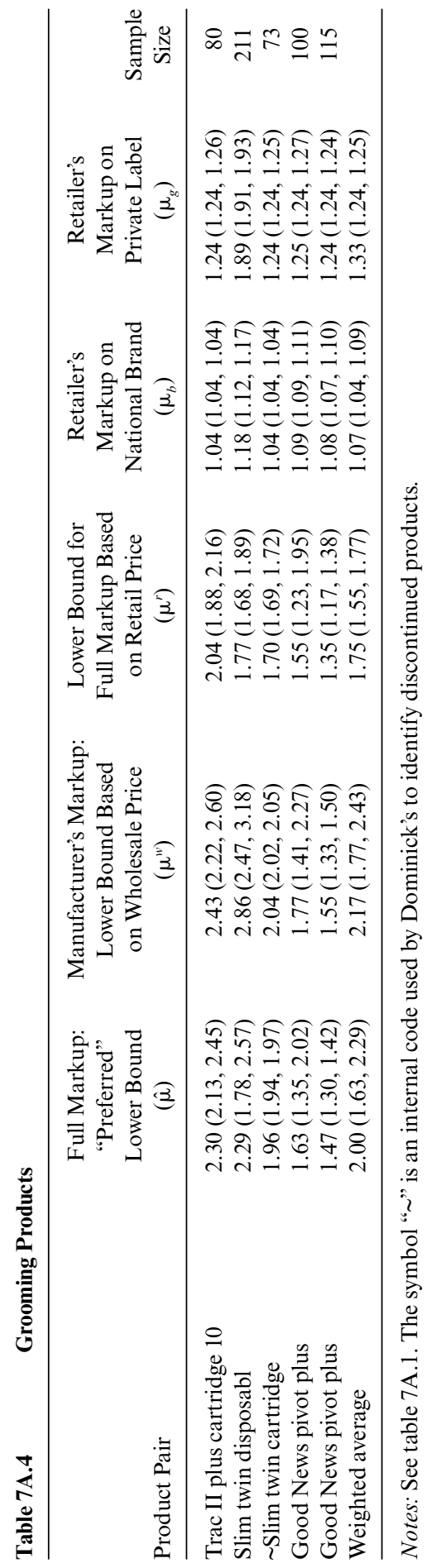




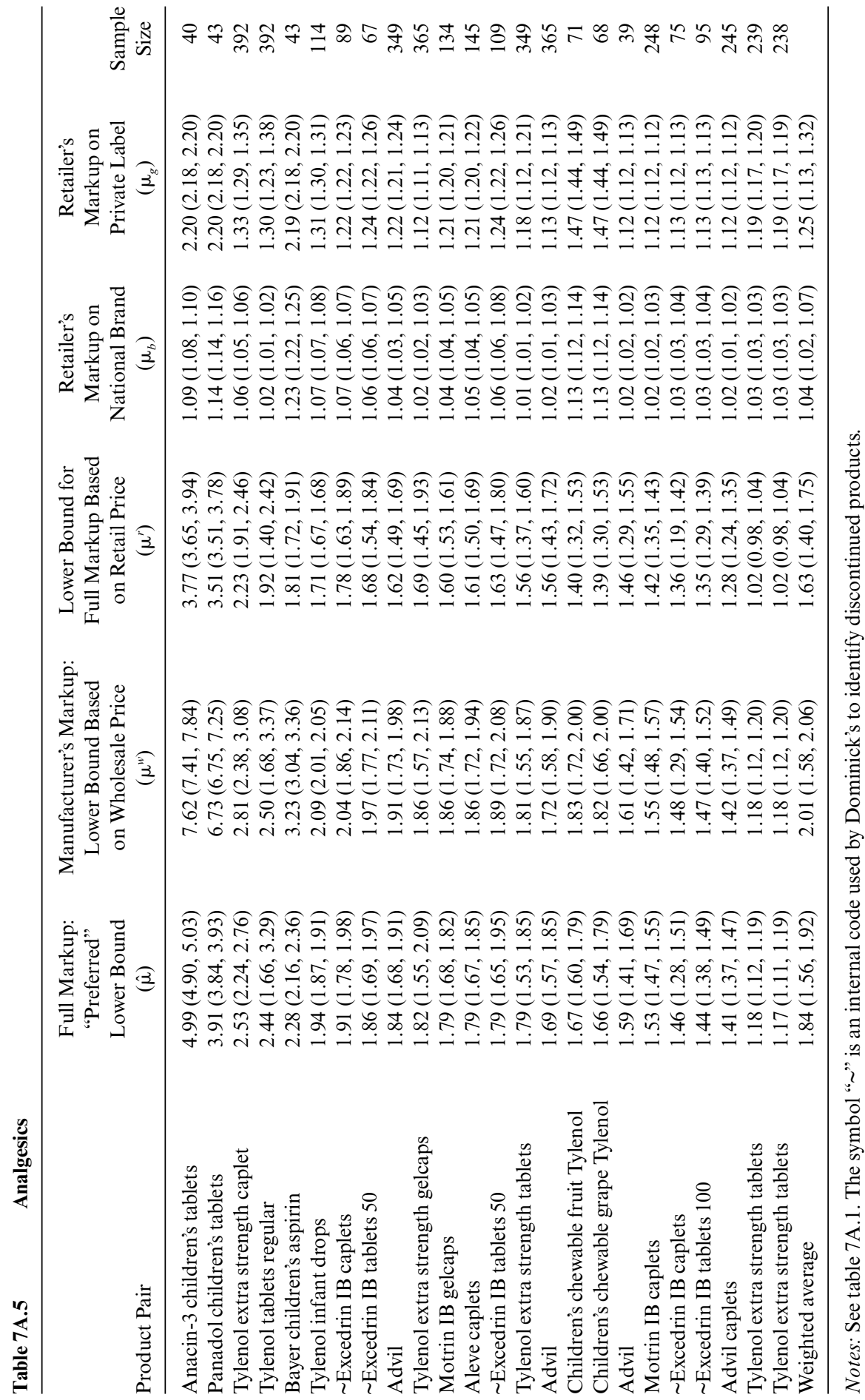




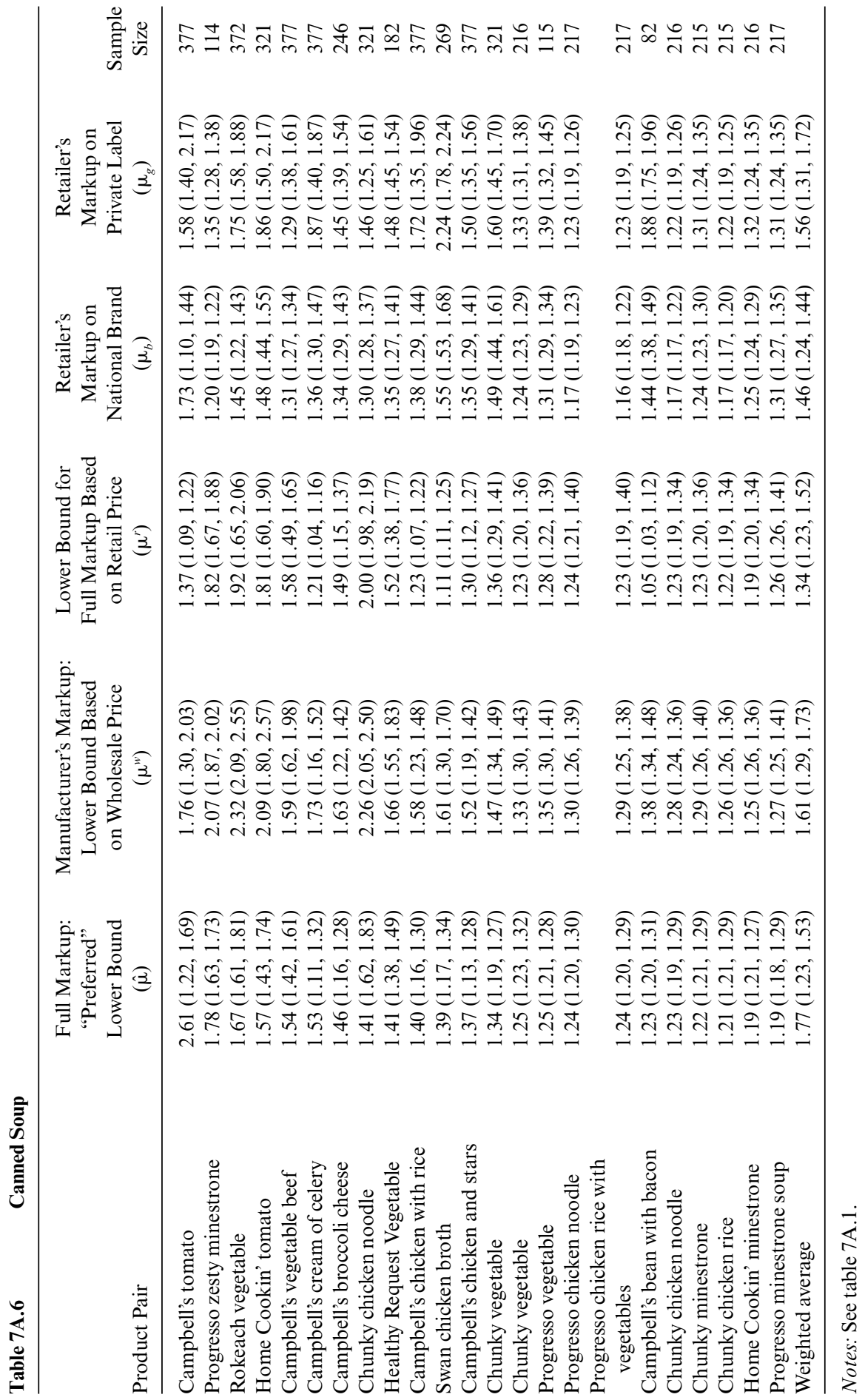




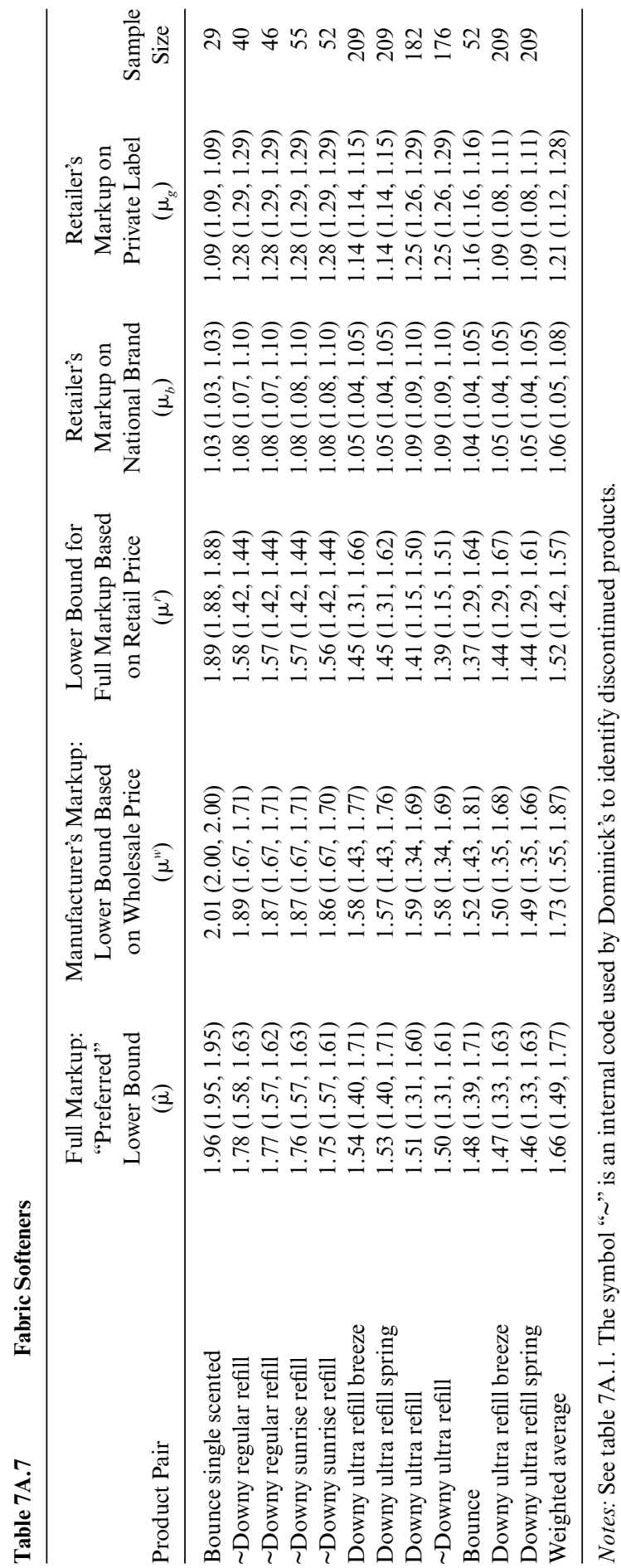




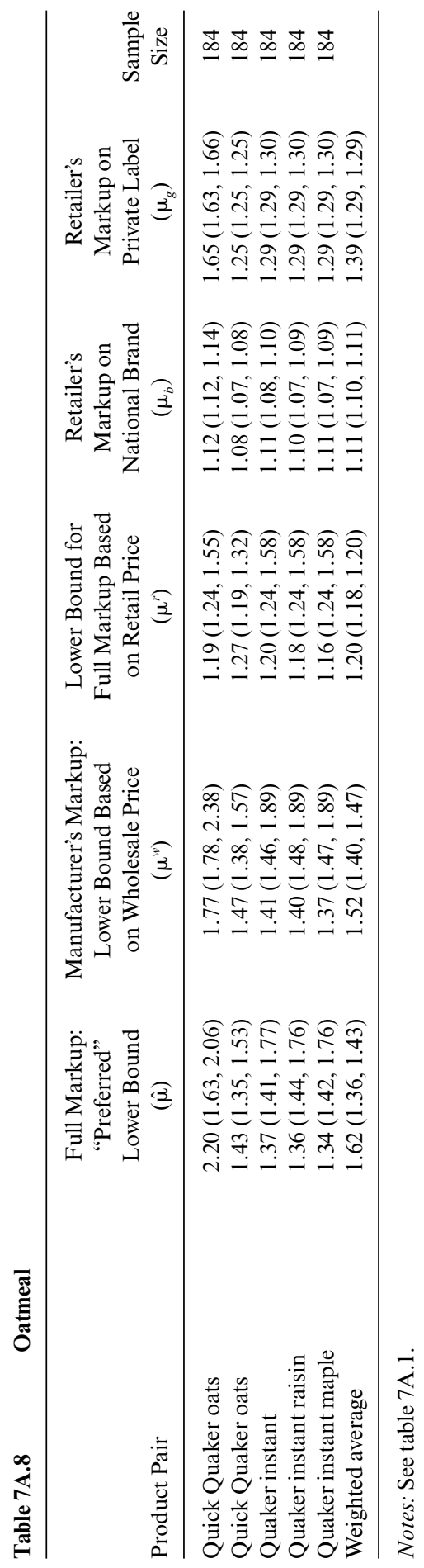




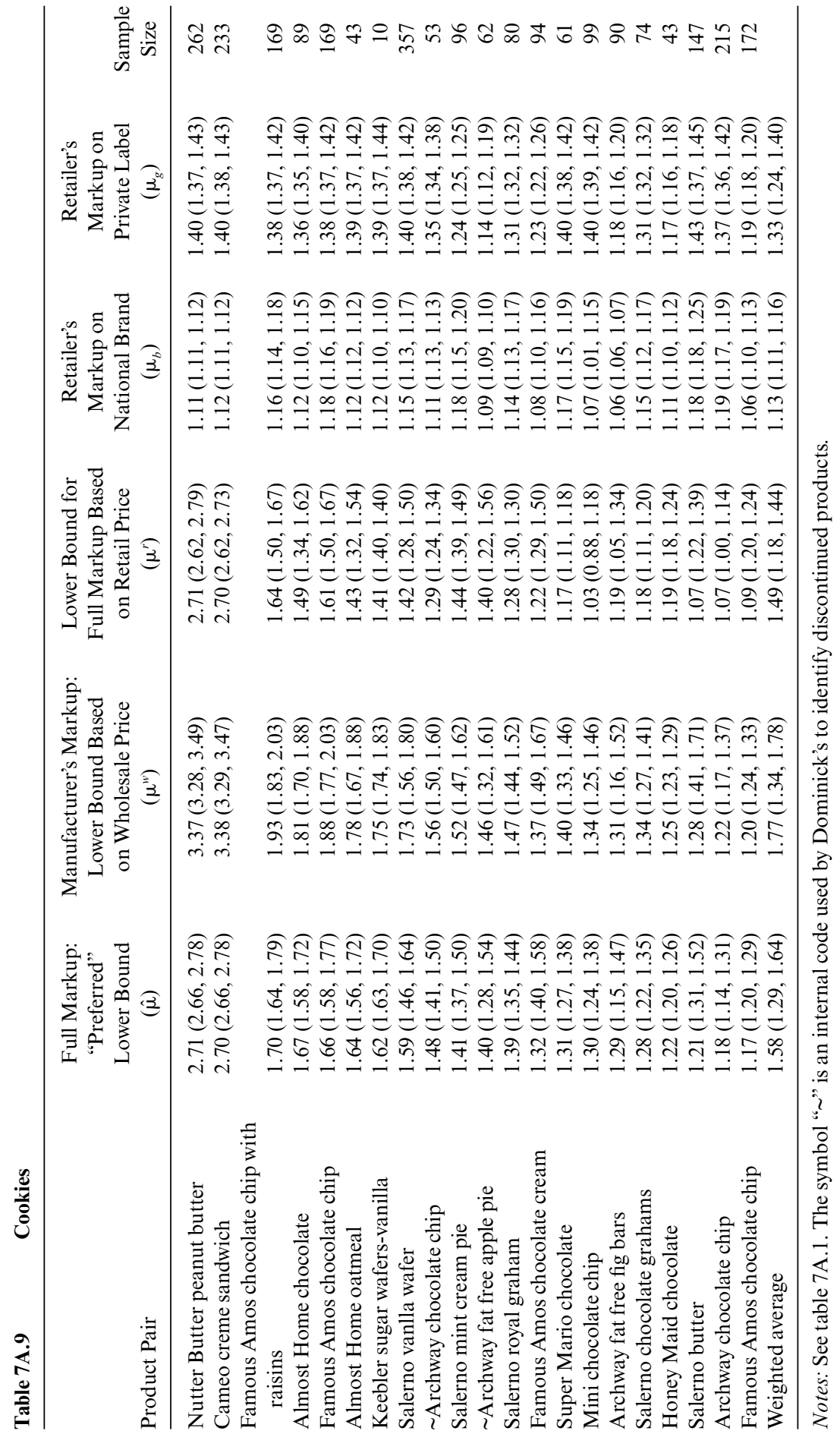




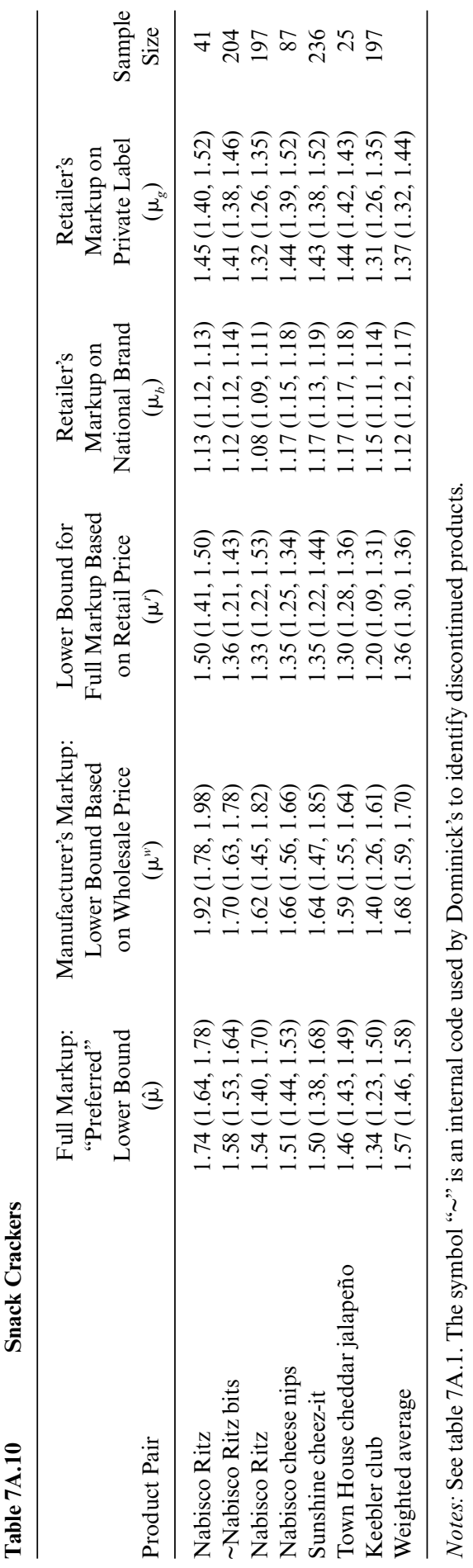




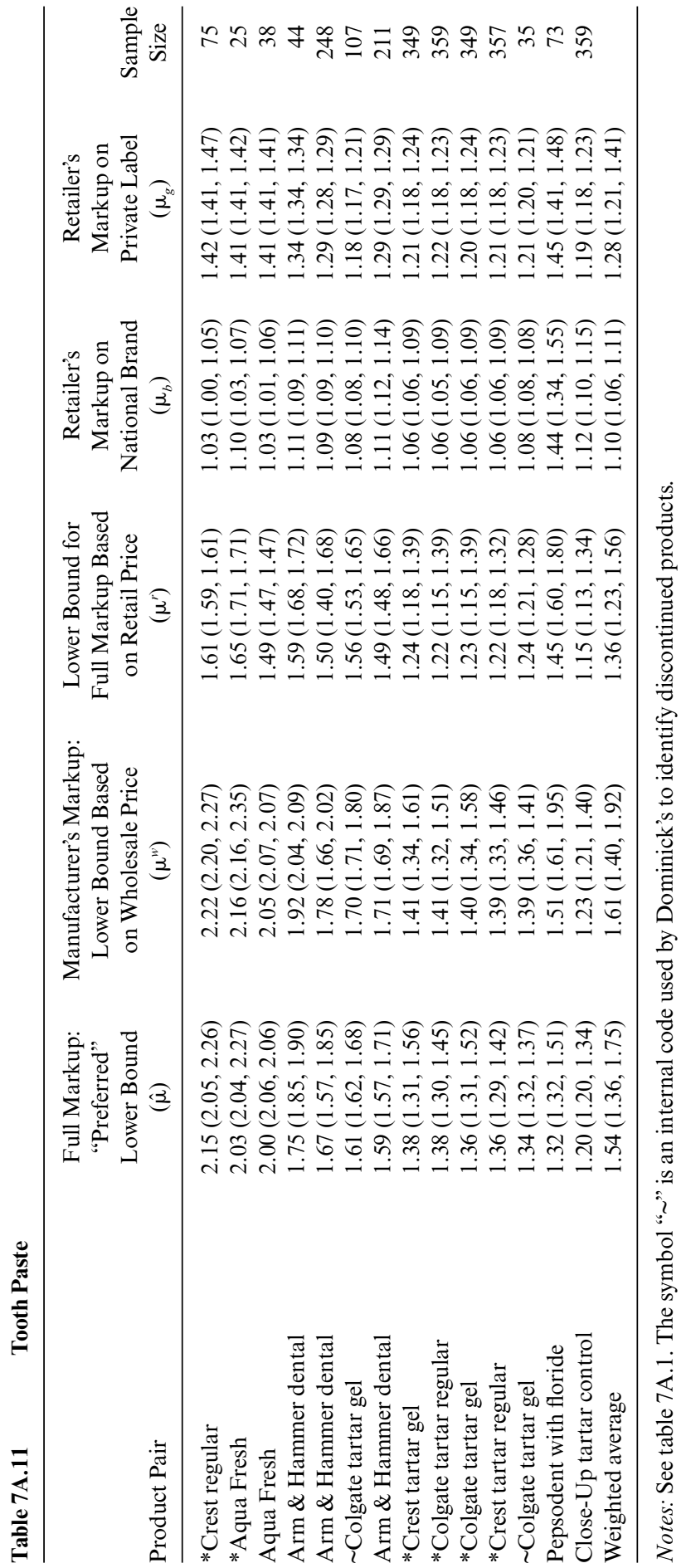




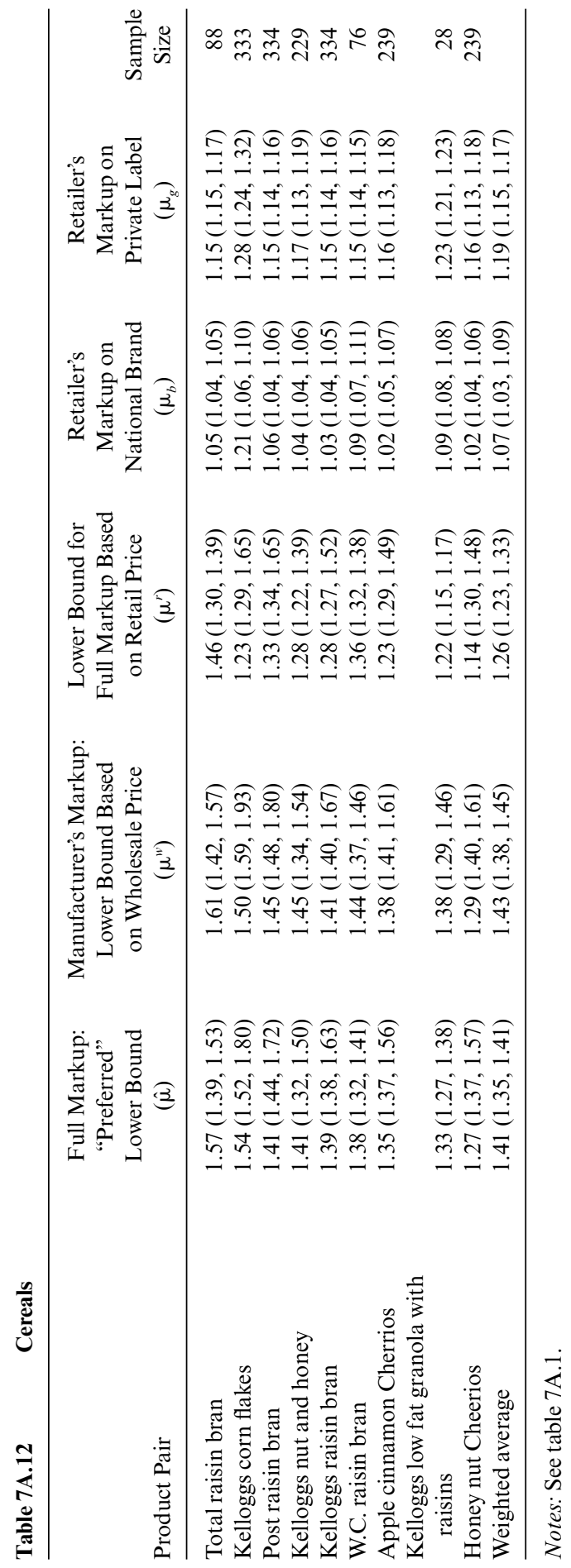




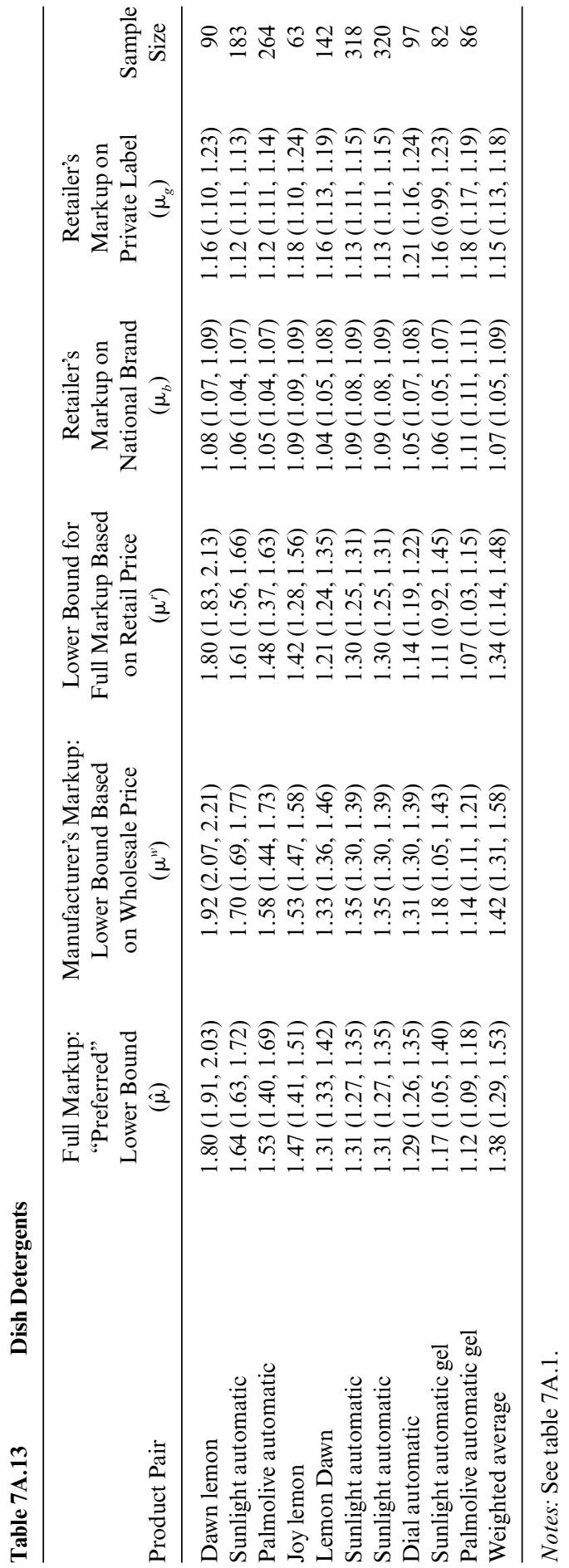




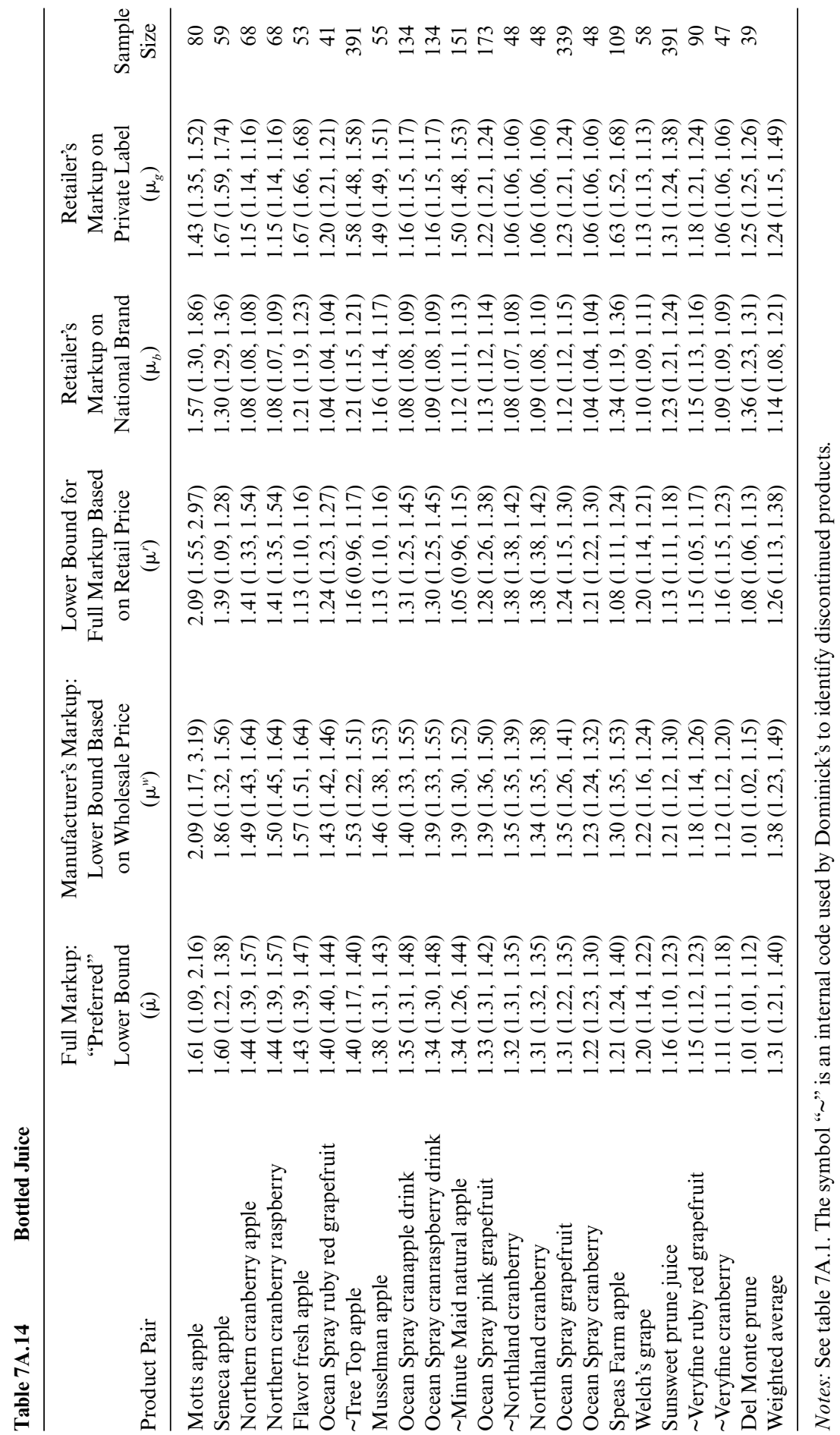




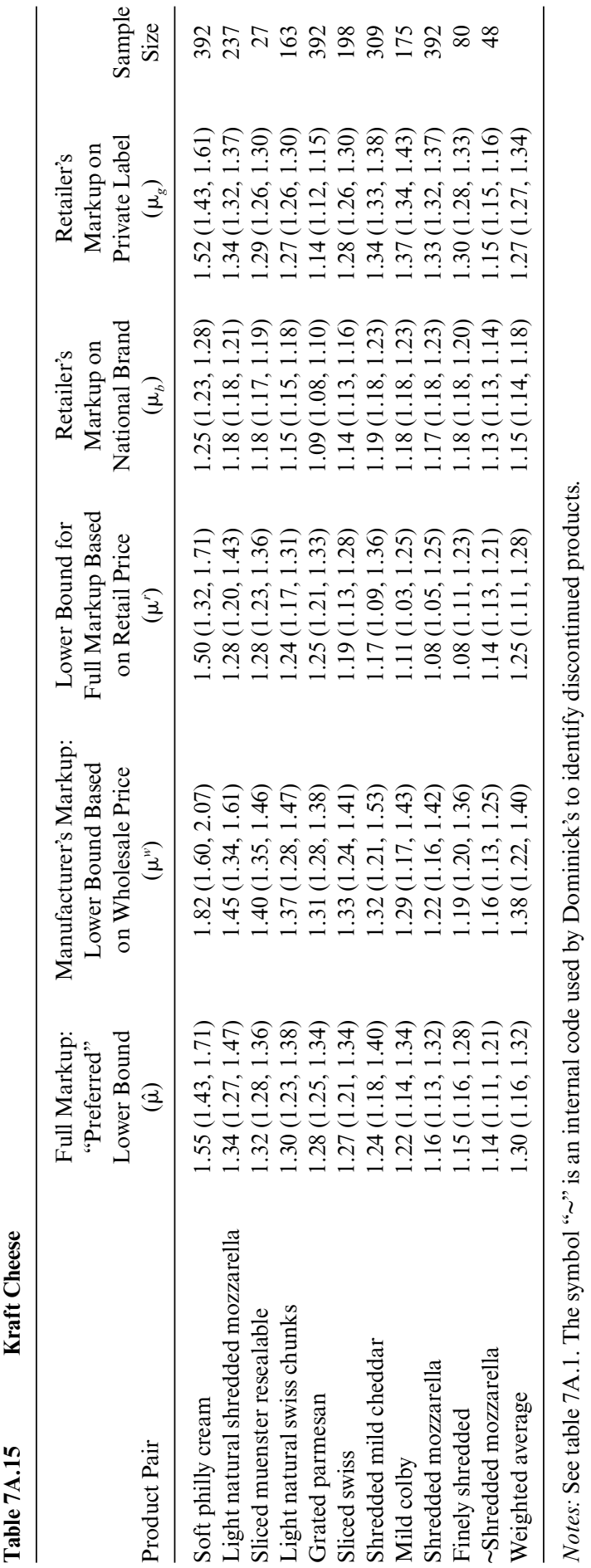




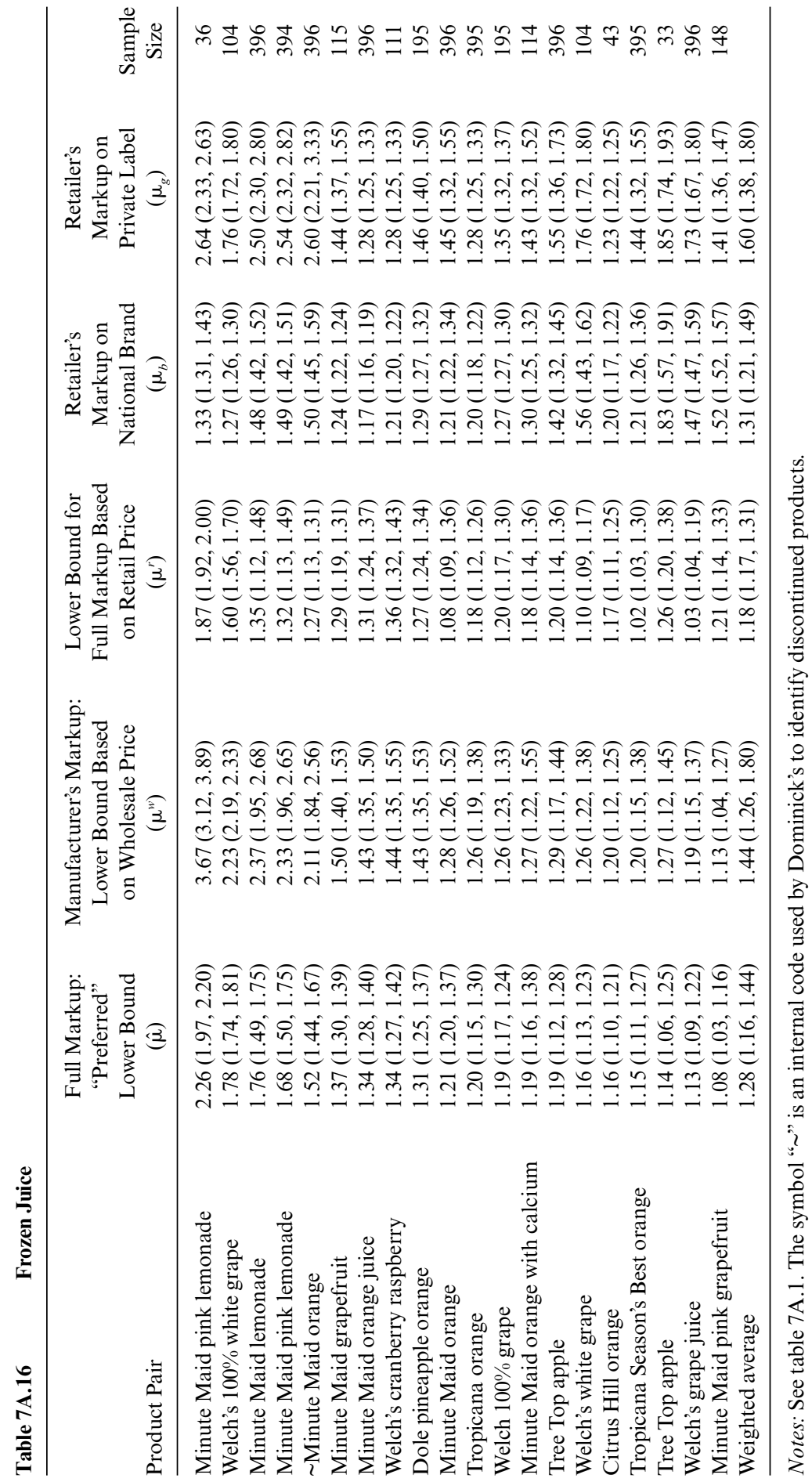




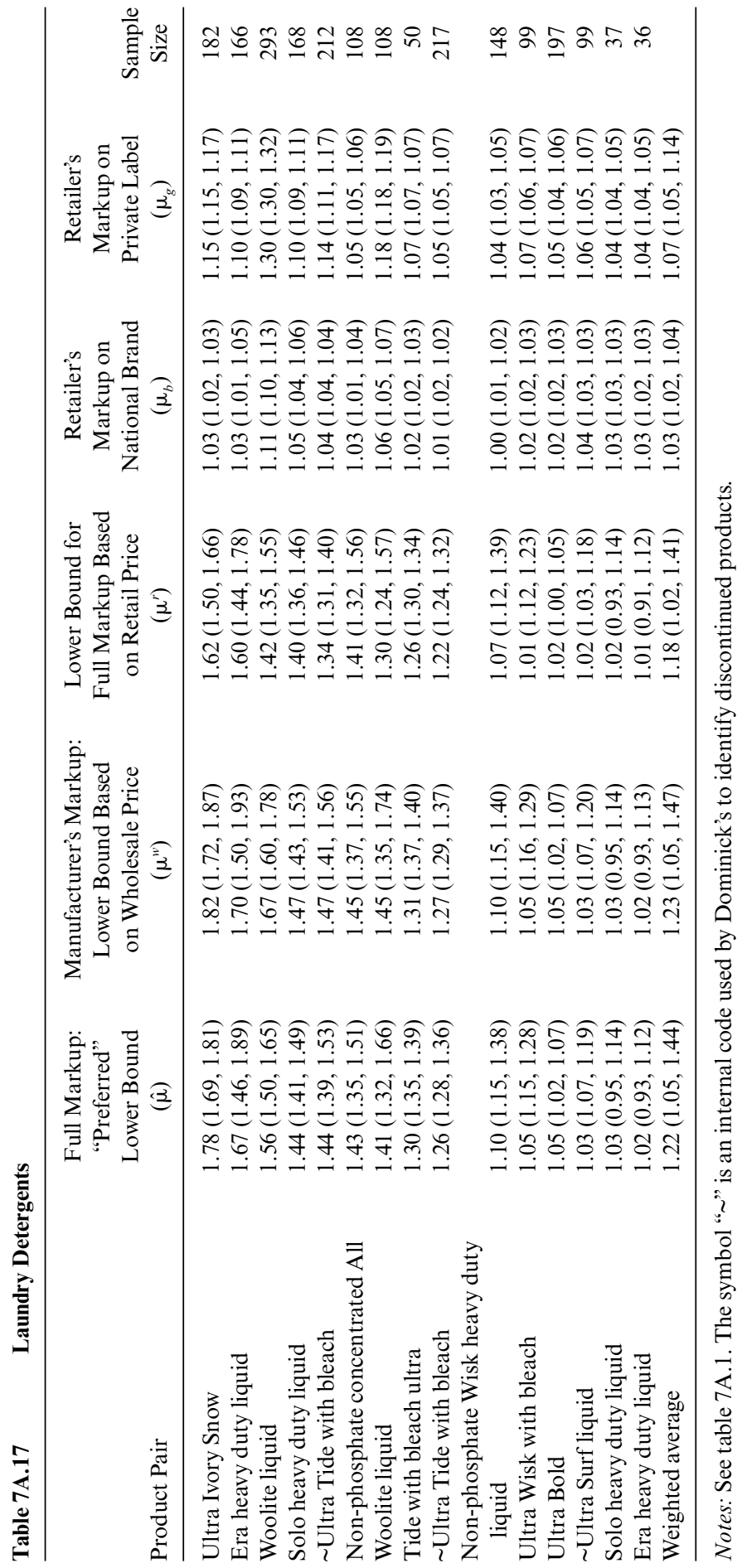




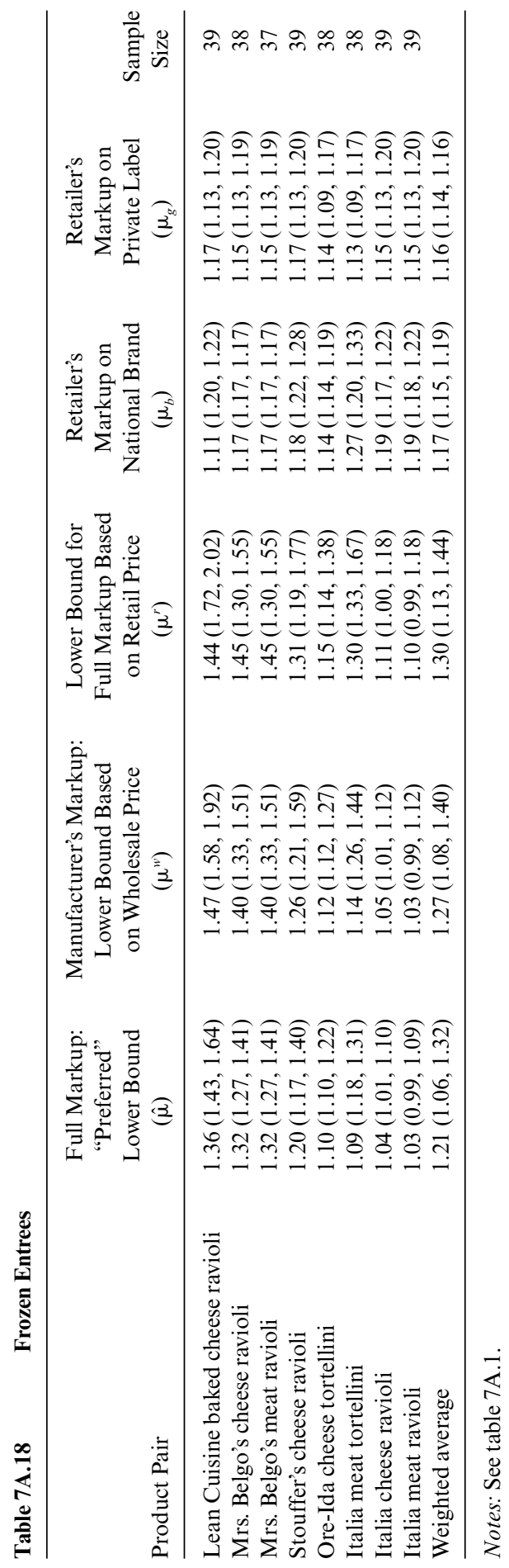




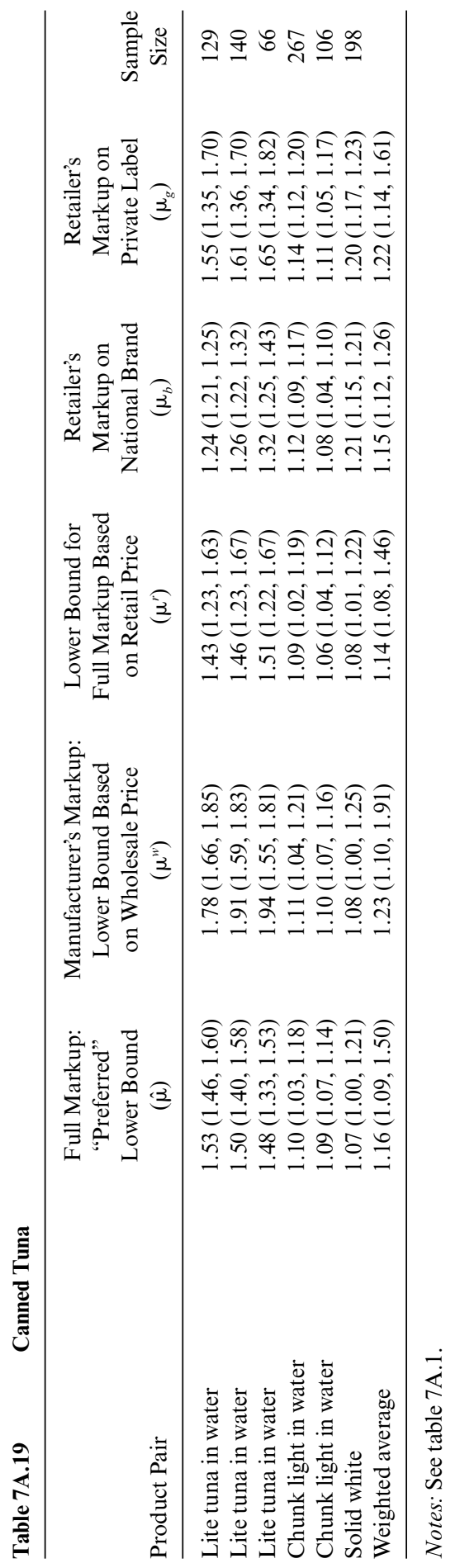




\section{References}

Basu, Susanto, and John Fernald. 1997. Are apparent productive spillovers a figment of specification error? Journal of Monetary Economics 36 (1): 165-88.

Bils, Mark J. 1986. The cyclical behavior of marginal cost and price. American Economic Review 77:838-57.

Brown, Charles, and James Medoff. 1989. The employer size-wage effect. Journal of Political Economy 97 (October): 1027-59.

- 1991. Cheaper by the dozen. Harvard Institute of Economic Research Working Paper no. 1557. Cambridge, Mass.: Harvard Institute of Economic Research.

Carlton, Dennis W., and Jeffrey M. Perloff. 1994. Modern industrial organization. New York: Harper Collins.

Chen, Yuxin, James D. Hess, Ronald T. Wilcox, and Z. John Zhang. 1999. Accounting profits versus marketing profits: A relevant metric for category management. Marketing Science 18 (3): 208-29.

Chevalier, Judith, Anil K. Kashyap, and Peter E. Rossi. 2000. Why don't prices rise during periods of peak demand? Evidence from scanner data. NBER Working Paper no. 7981. Cambridge, Mass.: National Bureau of Economic Research.

Cox Eighteenth Annual Promotional Practice Survey. 1996. Atlanta, Ga.: Cox Communications and Donnelly Marketing, Inc.

Dutta, Shantanu, Mark Bergen, and Daniel Levy. 2002. Price flexibility in channels of distribution: Evidence from scanner data. Journal of Economic Dynamics and Control 26:1845-1900.

Fitzell, Philip. 1982. Private labels: Store brands and generic products. Westport, Conn.: AVI Publishing.

- 1998. The explosive growth of private labels in North America. New York: Global Books.

Hall, Robert E. 1986. Market structure and macroeconomic fluctuations. Brookings Papers on Economic Activity, Issue no. 2:285-322. Washington, D.C.: Brookings Institution.

- 1988. The relation between price and marginal cost in U.S. industry, Journal of Political Economy 96:921-47.

Hausman, Jerry A. 1997. Valuation of new goods under perfect and imperfect competition. In The economics of new goods, ed. Timothy Bresnahan and Robert J. Gordon, 209-37. Studies in Income and Wealth, vol. 58. Chicago: University of Chicago Press.

Hausman, Jerry A., and Gregory K. Leonard. 1999. The competitive effect of a new product introduction: A case study. MIT, Department of Economics. Working Paper.

Hoch, Steve. 1995. How should national brands think about private labels? University of Chicago, Department of Marketing, Graduate School of Business. Working Paper.

Hoch, Steve, and Shumeet Banerji. 1993. When do private labels succeed? Sloan Management Review 34 (summer): 57-67.

Hoch, Steve, J. S. Kim, Alan Montgomery, and Peter Rossi. 1995. Determinants of store-level price elasticity. Journal of Marketing Research 32 (February): 43-75.

Lal, Rajiv, and Chakravarthi Narasimhan. 1996. The inverse relationship between manufacturer and retailer margins: A theory. Marketing Science 15 (2): 132-51.

Levy, Daniel, Shantanu Dutta, and Mark Bergen. 2002. Heterogeneity in price rigidity: Evidence from a case study using micro-level data. Journal of Money, Credit, and Banking, forthcoming. 
Levy, Daniel, Shantanu Dutta, Mark Bergen, and Robert Venable. 1998. Price adjustment at multiproduct retailers. Managerial and Decision Economics 19:81120.

Levy, Daniel, and Andrew Young. 2001. "The real thing": Nominal price rigidity of the nickel Coke, 1886-1959. Department of Economics, Bar-Ilan University and Department of Economics, Emory University. Working Paper.

Monroe, Kent B. 1990. Pricing: Making profitable decisions. 2d ed. New York: McGraw-Hill.

Morton, Feona Scott, and Florian Zettelmeyer. 2000. The strategic use of store brand in retailer-manufacturer bargaining. University of California, Berkeley, Department of Marketing, Haas School of Business. Working Paper.

Müller, Georg, Mark Bergen, Shantanu Dutta, and Daniel Levy. 2001. Price rigidity during holiday periods: The role of price adjustment costs. University of Minnesota, Department of Marketing, Carlson School of Management and Bar-Ilan University, Department of Economics. Working Paper.

Nevo, Aviv. 1997. Demand for ready to eat cereal and its implications for price competition, merger analysis, and valuation of new brands. Ph.D. diss., Harvard University.

- 2001. Measuring market power in the ready-to-eat cereal industry. Econometrica 69 (2): 265-306.

Quelch, John A., and David Harding. 1996. Brand versus private labels: Fighting to win. Harvard Business Review reprint 96109 (Jan.-Feb.): 99-109.

Rotemberg, Julio, and G. Saloner. 1986. A supergame-theoretic model of business cycle and price wars during booms. American Economic Review 76 (June): 390407.

Rotemberg, Julio, and Michael Woodford. 1996. Imperfect competition and the effects of energy price increases on economic activity. Journal of Money, Credit, and Banking 28 (4): 549-77.

Scherer, F. M. 1980. Industrial market structure and economic performance, 2nd ed. Boston: Houghton Mifflin.

Schmalensee, Richard. 1978. Entry deterrence in the ready to eat breakfast cereal industry. Bell Journal of Economics 9:305-27.

Sethuraman, Raj, and Catherine Cole. 1997. Why do consumers pay more for national brands than for store brands? Marketing Science Institute Report no. 97126. Cambridge, Mass.

Shaked, A. and J. Sutton. 1982. Relaxing price competition through product differentiation. Review of Economic Studies 49:3-13.

Slade, Margaret E. 1998. Optimal pricing with costly adjustment: Evidence from retail-grocery prices. Review of Economic Studies 65:87-107.

Steiner, Robert L. 1993. The inverse association between the margins of manufacturers and retailers. Review of Industrial Organization 8:717-40.

Supermarket Business. 1993. Fourth annual consumer expenditures study: From recession to reality. 49 (9): 35-56.

Sutton, John. 1991. Sunk cost and market structure. Cambridge, Mass.: MIT Press.

Tirole, Jean. 1989. The theory of industrial organization. Cambridge, Mass.: MIT Press. 


\section{Comment Julio Rotemberg}

This is an excellent paper, which contains a trove of interesting data on prices and costs. The thorough comparison between retail and wholesale prices of both nationally advertised brands and comparable products sold under private labels that the authors carry out turns out to convey important lessons for many issues in economics.

The authors focus on a very important magnitude, which they call the "ideal" markup. This is the ratio of the price paid by consumers for a nationally advertised good and the marginal cost of both producing the good and delivering it to the consumer. The gap between this price and this marginal cost gives the answer to a standard microeconomics question. This is the extent to which the sum of consumer and producer surplus increases when the final price is reduced sufficiently that the quantity sold increases by one unit. This magnitude is also a critical ingredient in macroeconomics because it answers the question of whether producers would continue to be willing to sell and distribute their goods if, either because prices are rigid or for some other reason, price falls by some percentage relative to this marginal cost.

Once one has the retail price of a good, one can obtain this gap if one knows how much it costs to produce an additional unit and how much it costs to deliver it to a customer. The paper's solution to these hard measurement problems is attractive on a number of counts. The authors suppose that Dominick's acquisition price of a private-label good that is similar to a nationally branded good is generally no smaller than the marginal cost of producing and delivering to the supermarket an additional unit of the branded good. They also suppose that the supermarket's margin between the price it pays for the branded good and the price at which it sells the good is no smaller than the supermarket's own marginal cost of distributing the good. Thus, the sum of the private label's wholesale price and the margin on branded goods is an underestimate of the full marginal cost of delivering an additional unit to the consumer, and the ratio of the price to this sum is an underestimate of the markup they seek to measure.

Although no assumption that simplifies calculations so much can be valid 100 percent of the time, I find this approach very compelling. Although one might initially suspect that private-label goods are cheaper to manufacture than branded goods so that their low wholesale price is not informative, many of Dominick's private-label goods proudly proclaim in their package their similarity in content and appearance to well-publicized branded goods. Indeed, one thing I would have liked to see is more soft information from the authors about the relative appearances of the pairs of goods they consider. Broad surveys that show that good private-label goods

Julio Rotemberg is the William Ziegler Professor of Business Administration at Harvard Business School and a research associate of the National Bureau of Economic Research. 
are quite often of high quality and not cheap to manufacture are in some ways less compelling than particular comparisons for the goods in their sample because private-label goods vary a great deal in quality.

Interestingly, the magnitude that seems harder to measure in this study is the price paid by consumers, because the retail price the authors measure does not include coupons and rebates. Still, it is quite clear that some consumers pay the full retail price for branded goods at least some of the time, so that the authors have a valid measurement of a particular ratio between price and marginal cost. What is less clear is the fraction of the economy that involves the high markups they find in their analysis because, even within this sector, many transactions involve smaller markups.

For macroeconomics, the ratios they consider matter because they measure how much price can be squeezed relative to marginal cost while maintaining an incentive to sell. The authors' calculation essentially supposes that the retail margin cannot be squeezed, so that the entire ability to absorb lower prices falls on the manufacturer. I see the ratio of wholesale prices charged by branded goods and private-label goods as, in some ways, a more direct measurement of the extent to which manufacturers of branded goods would continue to deliver products even if their prices fell. It is thus good to see these numbers reported as well, and it is interesting that they are similar to those of their ideal markup.

Let me close by offering some thoughts on the microeconomic implications of this paper's findings. The first is that it is far from clear that the ideal markup the authors compute says much about the extent to which branded goods' prices are too high from a social point of view. It is true that lower prices would increase producer and consumer surplus, if advertising and research and development (R\&D) expenditures were held constant. However, firms would almost certainly not hold these expenditures constant if they were forced by an omniscient planner to lower their prices. It is more likely that such a squeezing of margins would lower the manufacturer's incentive to carry out R\&D and advertising. The resulting fall in $R \& D$ could be costly, particularly because the fact that private labels free-ride on branded products by copying their designs suggests that the incentives for $R \& D$ in this industry may actually be too low. If advertising expenditures are socially useful - as they can be, for example, in the model of Becker and Murphy (1993) - reductions in these expenditures could be deleterious as well.

Once one focuses on R\&D and advertising expenditures, the natural question that poses itself is whether the ratio of these expenditures to other costs is of the same order of magnitude as the ratio of branded wholesale prices to private-label wholesale prices. If this is the case, one could conclude that these high markups are simply necessary to cover these additional costs. This in no way reduces the interest in the paper's finding that these markups are high, although it would suggest that rents in these industries are dissipated in a relatively straightforward way. 
The paper also contains a second set of fascinating facts that raise important microeconomics issues. In particular, the paper shows that the ratios of the four prices considered here for each pair of goods (i.e., the retail and wholesale prices for both members of each pair) vary quite dramatically across goods, even within narrow product categories. Trying to understand some of these variations seems extremely worthwhile. Indeed, some of the relative prices reported here seem to cry out for explanation. This seems particularly true of the "negative" margin between the retail and the wholesale price of certain soft drinks. This almost makes one worry about the authors' ability to measure the amount that Dominick's actually paid for its products.

One source of variation in the ratio of branded to private-label retail prices is obviously the extent to which branded products are seen as superior by customers (and this may explain the huge markups in toothbrushes). Open questions fall into two categories, however. The first is whether other ratios, such as the ratios of wholesale prices or the difference in branded and private-label retail margins, are also explainable in these terms or whether they hinge on variables related to the manufacturing industry's structure. The other is whether any of these ratios, including the ratio between the retail prices of the products in each pair, are related to the extent to which there is price discrimination in each product.

\section{Reference}

Becker, Gary S., and Kevin M. Murphy. 1993. A simple theory of advertising as a good or bad. The Quarterly Journal of Economics 108 (4): 941-64. 